\title{
Comparative genomics of the white-rot fungi, Phanerochaete carnosa and P. chrysosporium, to elucidate the genetic basis of the distinct wood types they colonize
}

Hitoshi Suzuki ${ }^{1}$, Jacqueline MacDonald ${ }^{1}$, Khajamohiddin Syed ${ }^{2}$, Asaf Salamov ${ }^{3}$, Chiaki Hori ${ }^{5}$, Andrea Aerts ${ }^{3}$, Bernard Henrissat ${ }^{4}$, Ad Wiebenga ${ }^{8}$, Patricia A vanKuyk ${ }^{8}$, Kerrie Barry ${ }^{3}$, Erika Lindquist ${ }^{3}$, Kurt LaButti ${ }^{3}$, Alla Lapidus ${ }^{3}$, Susan Lucas ${ }^{3}$, Pedro Coutinho ${ }^{4}$, Yunchen Gong ${ }^{7}$, Masahiro Samejima ${ }^{5}$, Radhakrishnan Mahadevan", Mamdouh Abou-Zaid ${ }^{6}$, Ronald P de Vries ${ }^{8}$, Kiyohiko Igarashi ${ }^{5}$, Jagjit S Yadav², Igor V Grigoriev ${ }^{3}$ and Emma R Master ${ }^{1 *}$

\begin{abstract}
Background: Softwood is the predominant form of land plant biomass in the Northern hemisphere, and is among the most recalcitrant biomass resources to bioprocess technologies. The white rot fungus, Phanerochaete carnosa, has been isolated almost exclusively from softwoods, while most other known white-rot species, including Phanerochaete chrysosporium, were mainly isolated from hardwoods. Accordingly, it is anticipated that $P$. carnosa encodes a distinct set of enzymes and proteins that promote softwood decomposition. To elucidate the genetic basis of softwood bioconversion by a white-rot fungus, the present study reports the $P$. carnosa genome sequence and its comparative analysis with the previously reported $P$. chrysosporium genome.
\end{abstract}

Results: $P$. carnosa encodes a complete set of lignocellulose-active enzymes. Comparative genomic analysis revealed that $P$. carnosa is enriched with genes encoding manganese peroxidase, and that the most divergent glycoside hydrolase families were predicted to encode hemicellulases and glycoprotein degrading enzymes. Most remarkably, P. carnosa possesses one of the largest P450 contingents (266 P450s) among the sequenced and annotated wood-rotting basidiomycetes, nearly double that of $P$. chrysosporium. Along with metabolic pathway modeling, comparative growth studies on model compounds and chemical analyses of decomposed wood components showed greater tolerance of $P$. carnosa to various substrates including coniferous heartwood.

Conclusions: The P. carnosa genome is enriched with genes that encode P450 monooxygenases that can participate in extractives degradation, and manganese peroxidases involved in lignin degradation. The significant expansion of P450s in P. carnosa, along with differences in carbohydrate- and lignin-degrading enzymes, could be correlated to the utilization of heartwood and sapwood preparations from both coniferous and hardwood species.

Keywords: Phanerochaete carnosa, Comparative genomics, Phanerochaete chrysosporium, Softwood degradation

\footnotetext{
*Correspondence: emma.master@utoronto.ca

'Department of Chemical Engineering \& Applied Chemistry, University of

Toronto, 200 College Street, Toronto, ON M5S 3E5, Canada

Full list of author information is available at the end of the article
} 


\section{Background}

The lignocellulose fraction of plant cell walls is the most abundant renewable carbon source on earth, and is a key resource for substituting petroleum in the production of energy, chemicals and materials. Among the various types of lignocellulosic biomasses, softwood is the predominant form of land plant biomass in the Northern hemisphere [1]. Softwood (coniferous) and hardwood (deciduous) fiber mainly differ in the structure and composition of hemicellulose and lignin components. For instance, glucuronoxylan comprises approximately $20-30 \%$ of the secondary cell wall polysaccharides in hardwood, while galactoglucomannan is the main hemicellulose in secondary cell walls of softwood. Moreover, softwoods contain mainly guaiacyl lignin, whereas hardwoods contain varying ratios of syringyl and guaiacyl lignins [2]. The recalcitrance of softwood lignocellulose to bioprocess technologies has been attributed to its higher lignin content, smaller pore size, and fewer hemicellulose-derived acetyl groups in comparison with hardwood [3].

Although relatively few organisms are known to effectively utilize all components of lignocellulose, white-rot basidiomycetes transform cellulose, hemicellulose and lignin, and so are regarded as essential contributors to global carbon cycling [4]. While most known white-rot species, including the model fungus Phanerochaete chrysosporium [5,6], have been mainly isolated from hardwoods, the white-rot basidiomycete, Phanerochaete carnosa, has been isolated almost exclusively from softwoods, including Abies balsamea (balsam fir), Abies concolor (white fir), and Pinus ponderosa (ponderosa pine) [7]. Previous studies have revealed differences in gene expression between P. carnosa and P. chrysosporium, suggesting that $P$. carnosa may possess an enzyme complement that is efficient for softwood bioconversion. For example, proteomic characterization of $P$. carnosa secretomes showed that $P$. carnosa produces a glycoside hydrolase (GH) family 2 mannanase, a multicopper oxidase, and glycopeptides that likely participate in carbohydrate and lignin degradation [8], which were not previously identified in proteomic analysis of $P$. chrysosporium [6,9]. More recent transcriptomic analyses evaluated gene expression in $P$. carnosa grown on various softwood species (white spruce, lodgepole pine, and balsam fir), as well as a hardwood (sugar maple). Notably, transcripts predicted to encode lignin-degrading activities (particularly manganese peroxidases) were more abundant than those predicted to encode carbohydrateactive enzymes [10], which is in contrast to earlier studies of $P$. chrysosporium grown on wood that revealed comparatively high levels of transcripts encoding carbohydrate-active enzymes [11].

Key requirements for the biotransformation of particular biomass resources could be elucidated through comparative analysis of closely related lignocellulose-degrading fungi having different substrate preferences. For instance, genomic comparison of $P$. chrysosporium and the softwood-degrading, model brown-rot fungus, Postia placenta, revealed that brown-rot is characterized by the contraction of multiple gene families, including cellobiohydrolases and cellulose-binding domains [12]. Moreover, comparative analysis of Aspergillus genomes identified correlations between genome content, plant polysaccharide degradation, and respective biotope [13]. Given the apparent differences in substrate preference of $P$. carnosa and $P$. chrysosporium, and their phylogenetic similarity based on internal transcribed spacer (ITS) region sequences [14], it is anticipated that comparative analysis of $P$. carnosa and $P$. chrysosporium genomes could reveal enzymes and metabolic pathways that are key to efficient biotransformation of recalcitrant softwood feedstocks. Accordingly, the present study reports the first analysis of the $P$. carnosa draft genome, and compares $P$. carnosa and $P$. chrysosporium in terms of genome composition and organization, as well as growth on model and woody substrates. These analyses revealed significant expansion of P450 genes in P. carnosa compared to P. chrysosporium, and highlighted several differences in carbohydrate active enzymes and lignin-degrading enzymes, which may facilitate softwood utilization by $P$. carnosa.

\section{Results and discussion}

\section{Assembly and overview of the $P$. carnosa genome}

The net length of the $P$. carnosa genome sequence was $46.3 \mathrm{Mb}$, and while distributed over 1137 scaffolds, the six largest scaffolds contained half of the total sequence and $57 \%$ of the 13,937 predicted genes (Additional file 1: Table S1, Table S2, Table S3). A summary of functional annotations by several classifications is shown in Additional file 1: Table S4. Of these genes, those predicted to encode P450 monooxygenases, MFS transporters, and signaling proteins (e.g. WD40 and protein kinases), comprised the largest families based on PFAM domains of translated sequences, and were expanded relative to other Basidiomycetes (Additional file 1: Table S5). Notably, the P. carnosa genome has 503 tandem gene duplication regions containing a total of 1660 genes, significantly higher numbers than the $P$. chrysosporium genome, which contains 305 duplication regions with 865 genes. Indeed, most of the top 50 PFAM domains are expanded in $P$. carnosa relative to $P$. chrysosporium (Additional file 1: Table S5) and these are largely responsible for the differences in gene count and genome size between the two organisms.

A synteny display based on orthologous proteins in $P$. carnosa and $P$. chrysosporium revealed significant rearrangement in the evolutionary history of these two Phanerochaete genomes (Figure 1). Most of the 


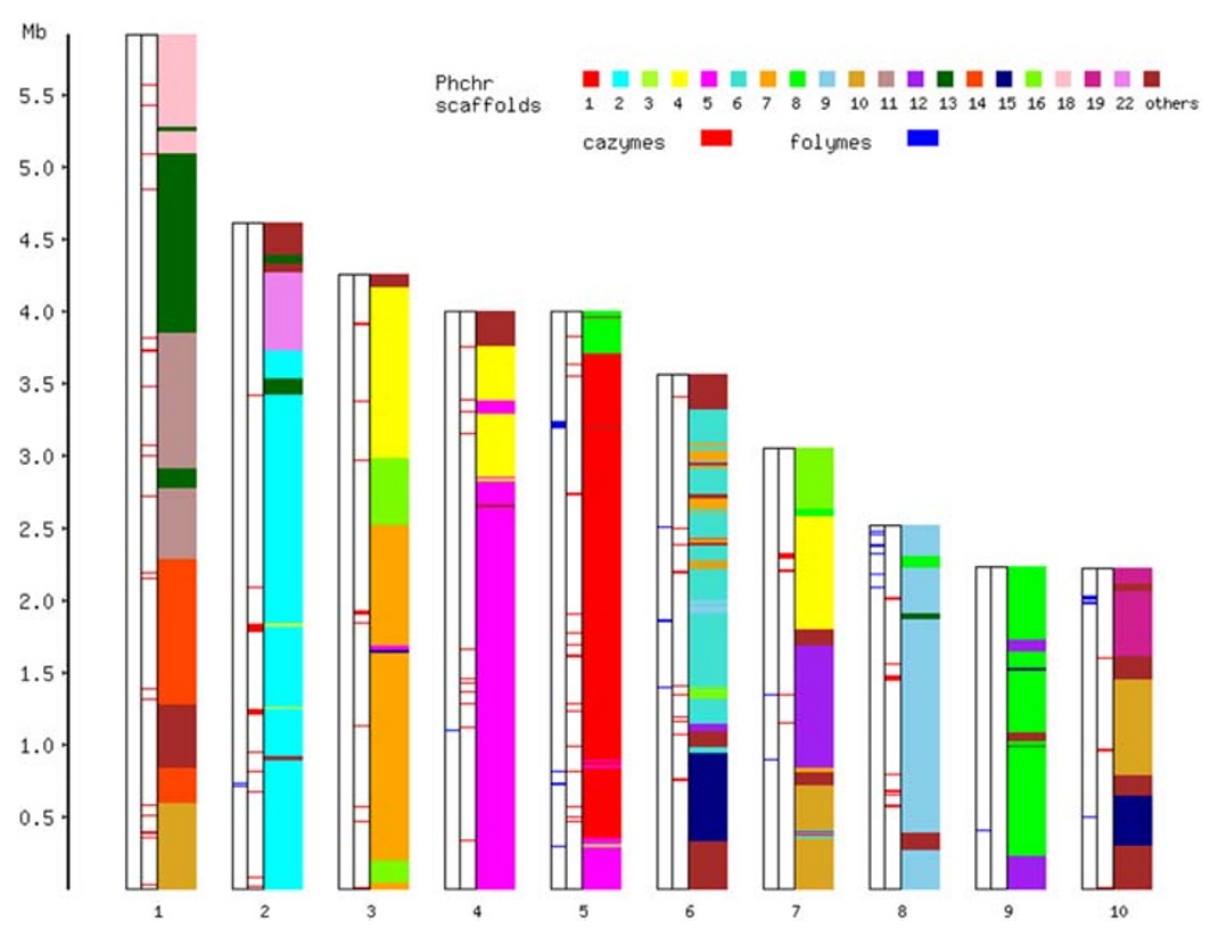

Figure 1 Syntenic regions of the 10 largest scaffolds of $P$. carnosa with scaffolds of $P$. chrysosporium. Scaffolds are shown as vertical bars, sequence starting from bottom to top, where the length of scaffolds is proportional to sequence length (largest: scaffold_1; smallest: scaffolds 9 and 10). Colors on the scaffolds refer to positions of genes that are the best homologs (orthologs) to corresponding P. chrysosporium scaffolds of the same color. Distribution of genes encoding CAZymes (red bars) and FOLymes (blue bars) across the scaffolds are also shown to the left of each scaffold.

carbohydrate- active enzymes [15] were distributed across the ten largest scaffolds of the $P$. carnosa genome sequence. While the glycoside hydrolase (GH) families GH7 and GH3 were enriched on scaffold_2, and the GH5 family was enriched on scaffold_4, most carbohydrate-active enzymes (CAZymes) were only loosely clustered. By contrast, six of the seven predicted manganese peroxidases (MnPs) were located on scaffold_5, and three of the four predicted lignin peroxidases (LiPs) were located on scaffold_10 (Additional file 2: Table S6), indicating that cluster formation of MnPs and LiPs is much tighter than that of CAZymes.

A primary aim of the current analysis was to compare the genomic content of $P$. carnosa and P. chrysosporium, and to correlate differences with their abilities to transform various compounds, including lignocellulosic substrates. Many previous reports demonstrate good correlation between genomic content and relative growth patterns on various carbon sources [13,16-18]. In those experiments, relative growth of a particular fungal species is determined by comparing the radius and density of the mycelia on a particular carbon source to that on Dglucose [19]. Relative growth patterns can then be compared between fungi, since differences in colony morphology and general differences in growth rates, are taken into account [16]. Accordingly, in addition to obtaining and analyzing the $P$. carnosa genome sequence, $P$. carnosa and $P$. chrysosporium were each grown in duplicate on 35 model carbon sources to determine how well respective genome contents correlated to relative growth measurements. Similar to previous analyses, relative growth of each fungus was determined separately by comparing the radius and density of mycelia on a particular carbon source to that on D-glucose; relative growth profiles were then compared between the two species (Additional file 3: Figure S1) [19]. Notably, the relative growth of $P$. carnosa on casein was higher than that observed for $P$. chrysosporium (Additional file 3: Figure S1), which is consistent with the considerable expansion of proteases encoded by P. carnosa (Additional file 1: Table S5). Similarly, where possible in the following sections, the growth profiles of $P$. carnosa and P. chrysosporium are correlated to relative occurrence of CAZymes and fungal oxidative lignin enzymes (FOLymes) encoded by these white-rot fungi.

\section{Carbohydrate active enzymes (CAZymes) and correlation to carbon catabolism}

Gene models encoding enzymes that were predicted to degrade, modify, or synthesize glycosidic bonds were annotated based on the CAZy classification scheme (Additional file 4: Table S7) [20-22]. The number of predicted CAZymes encoded by $P$. carnosa, $P$. chrysosporium 
and other Agaricomycotina genomes were also compared (Additional file 1: Table S8). As is usually found among wood decaying fungi, $P$. carnosa and $P$. chrysosporium encode a large repertoire of GH61 members (11 and 13 GH61s, respectively). Whereas the $P$. chrysosporium genome encodes two GH61 proteins that are located together on scaffold_10 (Phchr41563 and Phchr41650, where numbers indicate protein IDs from the JGI database), P. carnosa encodes a single ortholog (Phaca263097), which was highly expressed during growth on different wood samples (Additional file 3: Figure S2).

Although similar distributions of broad CAZy classifications were observed, closer inspection of particular CAZy families revealed notable differences between P. carnosa and P. chrysoporium (Figure 2). For instance, both families GH23 and GH25 encode lysozyme activity, and the absence of GH25 in P. carnosa appeared to be compensated by a gain of a GH23 enzyme. Likewise, the absence of GT50 ( $\alpha$-1,4-mannosyltransferase) enzymes and CBM18s in $P$. carnosa was balanced by a gain in genes that likely encode functionally similar proteins from families GT22 and CBM12. After family 1 CBMs, CBM13s comprise the largest CBM family encoded by $P$. chrysosporium whereas $P$. carnosa totally lacks members from this CBM family. Although sugar binding by $P$. chrysosporium CBM13s has not been characterized, xylooligosaccharides were shown to associate with a CBM13 binding domain from Streptomyces lividans [23]. Families GH5, GH79, CE16, and PL14 appear to have expanded in P. carnosa relative to $P$. chrysosporium (Figure 2 ), and contained a comparatively high fraction of proteins with relatively low identity $(<60 \%)$ to orthologous proteins in $P$. chrysosporium (Figure 3). While families GH5 and CE16 include enzymes involved in hemicellulose degradation, GH79 includes

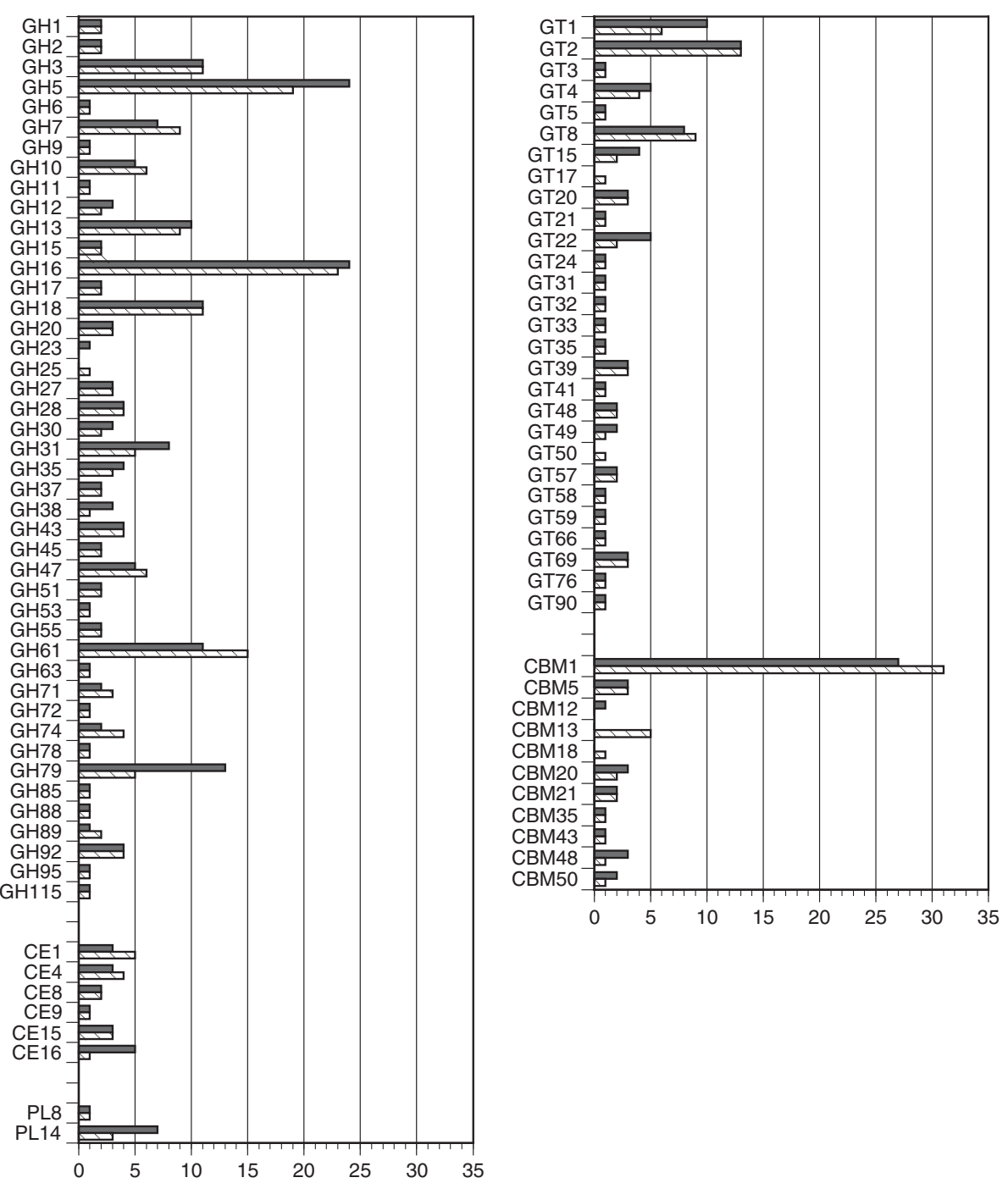

Figure 2 Distribution of CAZymes in P. carnosa (shadowed) and P. chrysosporium (lined). 


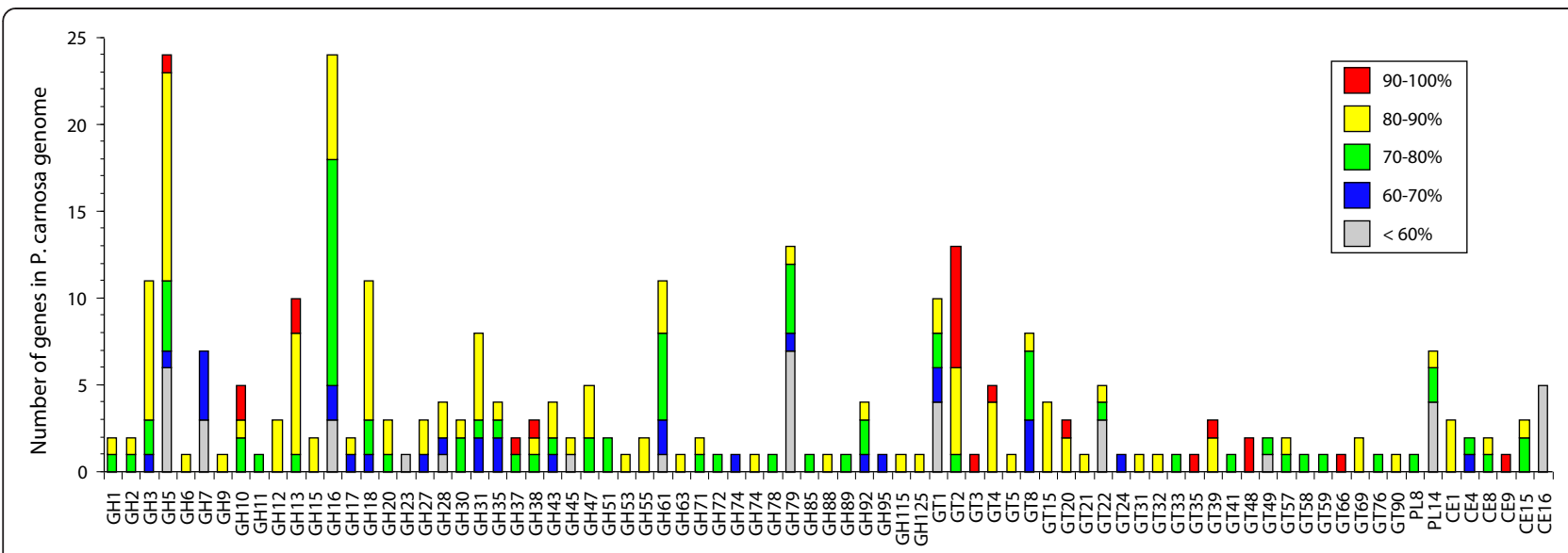

Figure 3 The distribution of percent identities of CAZyme members between $P$. carnosa and $P$. chrysosporium. For each query sequence ( $P$. carnosa genes), the highest percent identity in blastp was scored. The numbers of $P$. carnosa genes are indicated according to the percent identities.

enzymes involved in processing glycoproteins, including those found in plant cell walls [24].

Given the expansion of GH5 members in P. carnosa and P. chrysosporium (24 and 19 GH5s, respectively), along with the role of GH5 enzymes in degrading (galacto) glucomannan present in softwood, and proficient colony development of $P$. carnosa on guar gum (galactomannan) compared to birchwood xylan and pectin (Additional file 3: Figure S1), a phylogenetic analysis of GH5 protein sequences was performed to determine whether $P$. carnosa encodes new branches within this enzyme family (Additional file 3: Figure S3). This analysis identified one ortholog of $P$. chrysosporium $\beta$-mannanases (Phchr5115 and Phchr140501; Man5C and Man5D, respectively) in P. carnosa (Phaca248589), and revealed that Phaca168586 clusters on a neighboring branch and with an orthologous protein most similar to mannanases. Three additional GH5 sequences (Phaca253799, Phaca194783 and Phaca194761) formed a branch in the protein phylogeny that lacked representation from $P$. chrysosporium. Since Phaca168586 shares comparatively low identity (56\%) with the closest homolog in P. chrysosporium (Additional file 1: Table S9), and Phaca253799 was the only gene product from the unique phylogenetic branch that was upregulated in $P$. carnosa during growth on wood [10], Phaca168586 and Phaca253799 might be particularly interesting to target for future biochemical characterization.

\section{Sugar transport and intracellular metabolism}

In addition to the secretion of extracellular glycoside hydrolases, the ability to metabolize wood polysaccharides depends on the transport of resulting sugars and oligosaccharides, as well as intracellular conversion of these compounds.
Although genes encoding major facilitator superfamily (MFS) transporters appeared to have expanded in the $P$. carnosa genome, a phylogenetic analysis of predicted sugar transporters encoded by $P$. carnosa, $P$. chrysosporium, and other fungi formed eight sequence clusters, and revealed a similar distribution of $P$. carnosa and $P$. chrysosporium proteins (Additional file 3: Figure S4). A previous transcriptomic analysis of $P$. carnosa revealed comparatively high expression of Phaca263731 on nutrient rich medium [10], while Phchr137220, which also clusters in Group III, is upregulated in cellulose cultivations compared to glucose cultivations [25]. More interestingly, genes encoding four of the five Group VIII transport proteins were upregulated in P. carnosa grown on wood substrates (Additional file 3: Figure S4; [10]). This group comprises predicted cellobiose transporters previously found in yeasts and filamentous fungi [26-29]. Notably, a Group VIII cellodextrin transporter from $N$. crassa (NcNCU00801 and 08114) has been biochemically characterized [30], supporting that $P$. carnosa transporter proteins found in this group could have a role in cellobiose and/or cellodextrin uptake.

Sugar metabolism by $P$. carnosa and $P$. chrysosporium was further investigated by using corresponding genome sequences to reconstruct an entire metabolic network for each organism [31]. Gene products predicted to participate in central metabolism were then manually curated and expression levels were assigned from previous transcriptomic analyses (Additional file 5: Table S10). The results of this analysis revealed that the pentose catabolic pathway and the galacturonic acid pathway were induced in $P$. carnosa during growth on lignocellulosic substrates compared to nutrient medium, and that this response was accompanied by an increase in the expression of a transketolase, which catalyzes the conversion of D-xylulose-5-P to erythrose-4-phosphate 
in the pentose phosphate pathway. Enzymes that catalyze the first step in rhamnose and galactose metabolism were also induced in P. carnosa wood cultivations [10]. Similar trends were observed in $P$. chrysosporium, although it has fewer gene products in the corresponding metabolic pathways (Additional file 5: Table S10).

Notably, growth studies revealed that P. carnosa grew poorly on birchwood xylan and pectin (Additional file 3: Figure S1). Since the pentose and the galacturonic acid catabolic pathways likely promote the metabolism of pectin and xylan-derived sugars, metabolic models predicted herein suggest that poor growth of P. carnosa on pectin and xylan substrates could result from low expression of extracellular pectinase and xylanase enzymes or sugar transporters, rather than intracellular metabolism of hydrolysis products.

\section{Enzymes for lignin degradation, and conversion of related} aromatic compounds

The most evident difference in lignin-degrading activities encoded by $P$. carnosa and $P$. chrysosporium was the distribution of predicted manganese peroxidases $(\mathrm{MnP})$ and lignin peroxidases (LiP) (Additional file 1: Table S11) [32]. The $P$. carnosa genome encodes eleven Class II peroxidases: seven manganese peroxidases (MnP: Phaca256980, 144982, 256984, 256991, 256997, 94399, 262882) and four lignin peroxidases (LiP: Phaca212237, 263501, 213241, 152156). By comparison, P. chrysosporium encodes five MnPs and ten LiPs (Additional file 1: Table S11), suggesting that the two species might primarily rely on different peroxidase families for lignin decay. Growth profiling demonstrated that while both fungi grew well on wheat bran containing approx. $3 \%$ lignin, $P$. chrysosporium grew better than P. carnosa on cotton seed pulp (approx. 30\% lignin) (Additional file 3: Figure S1), suggesting a higher ligninolytic ability for $P$. chrysosporium. This result is consistent with the expansion of MnPs and reduction of LiPs in $P$. carnosa compared to P. chrysosporium, and the typically higher redox potential of LiP oxidoreductases.

A phylogenetic tree was previously constructed to infer the relationship of Class II peroxidases from P. carnosa and $P$. chrysosporium, and tree topology indicated gene expansion after $P$. chrysosporium and $P$. carnosa speciation [10]. Closer analysis of the protein phylogeny suggested that a common ancestor of $P$. carnosa and P. chrysosporium likely encoded three mnp genes and at least three lip genes. An analysis of intron distribution revealed the existence of up to seven conserved intron positions in the coding regions of $P$. carnosa and P. chrysosporium mnp genes, and up to ten conserved intron positions in the coding regions of the lips (Additional file 3: Figure S5). Most of these genes have lost one or two introns, suggesting a role for retrotransposition in gene expansion.
Among the nine predicted multi-copper oxidases (MCO) was a conventional ferroxidase (fet3; Phaca141262), and seven genes with high similarity (> 65\% amino acid identity) to $P$. chrysosporium mco4 (Phchr10581): these included Phaca261553, Phaca261563, Phaca149761, Phaca100787, Phaca100639, Phaca 149824, Phaca186926, which were all located on scaffold_8. Two additional genes, Phaca261609 and Phaca60261, were more closely related to $P$. chrysosporium $m c o 3$ and $m c o 2$, respectively. Notably, only two of these MCO-encoding genes, Phaca141262 (fet3) and Phaca100639 (mco4), appear to be upregulated during growth on wood [10]. The predicted cellobiose dehydrogenase (cdh: Phaca259608) and an ortholog to cir1 (cellulose-binding iron reductase, Phaca161126) were also up-regulated in $P$. carnosa during growth on wood [10]. As in the case of $P$. chrysosporium, $P$. carnosa does not appear to encode laccases sensu stricto. However, recent work with a Phanerochaete flavido-alba MCO shows that some members of the ferroxidase/laccase group may in fact have laccase activity [33].

Various enzymes are proposed to supply the $\mathrm{H}_{2} \mathrm{O}_{2}$ required for oxidase activity, the best established of which is glyoxal oxidase (GLOX, FOLy LDA3). The $P$. carnosa genome contains one glox gene (Phaca258261) and five related copper radical oxidases (cro: Phaca123913, Phaca259359, Phaca143144, Phaca263533, Phaca263528), compared to one glox and six related cro in P. chrysosporium (Additional file 1: Table S12). Phaca123913, Phaca259359, and Phaca143144 were most closely related to cro1, cro2, and cro6 of $P$. chrysosporium (Phchr259359, Phchr123913, Phchr258261), respectively. Both Phaca263533 and Phaca263528 were similar to cro3, cro4, and cro5, and contain repeated WSC domains of unknown function. These two WSC-containing cros are found within the lip physical gene cluster on scaffold_10. Notably, of the five copper radical oxidases identified here, only Phaca263528 was upregulated in P. carnosa during growth on wood [10].

\section{Cytochrome P450 monooxygenases}

Fungi encode a large repertoire of P450 genes [5,12,34], and in wood-rotting basidiomycetes in particular, P450s are known to be involved in the oxidation of phenolic and non-phenolic aromatic compounds with substructures similar to those occurring in lignin and extractive compounds that otherwise inhibit microbial growth [3538]. Accordingly, the distinct lignin composition of hardwoods and softwoods, as well as the variety of extractives produced by different wood species, provoked an interest to compare $P$. carnosa and $P$. chrysosporium in terms of the P450s they encode.

The current genomic analysis revealed that $P$. carnosa possesses one of the largest P450 contingents (266 P450s) among the sequenced and annotated wood- 
rotting basidiomycetes, much higher than that of $P$. chrysosporium (149 P450s) [34], somewhat larger than that of the brown rot fungus P. placenta (236 P450s) [12], and higher than any of the 31 fungal genomes recently reported by Floudas et al. [18]. Among the large number of tandem gene duplication events in the $P$. carnosa genome, the largest tandemly duplicated gene family is P450 with 38 duplication regions resulting in 80 genes, while corresponding numbers in the $P$. chrysosporium genome are 15 and 23 (Additional file 1: Table S13). Roughly 33\% of the P450 genes encoded by P. carnosa appear to be tandemly duplicated. According to the phylogenetic analysis, tandem duplication of at least 15 P450 genes occurred after divergence from $P$. chrysosporium. For example, four tandemly duplicated genes found in scaffold 7 (1419983-1433634) were 80-90 identical, and shared roughly $60 \%$ identity with the best homo$\log$ in P. chrysosporium.

The 266 P450s of $P$. carnosa were grouped into 10 known P450 clans, 36 families and 77 subfamilies, with
CYP64 being the largest clan with 124 members (Figure 4, Additional file 1: Table S14). In comparison to P. chrysosporium, several P450 clans (CYP52, CYP53, CYP54, CYP64, CYP67, CYP534 and CYP547) and many families had expanded in P. carnosa (Figure 5A and B). Interestingly, CYP64 and CYP52 were nearly doubled in P. carnosa and genes from these clans represented over half of the 28 unique P450 gene transcripts that were upregulated in P. carnosa wood degrading cultures ([10], Additional file 1: Table S15).

\section{Transformation of softwood and hardwood components} by $P$. carnosa and $P$. chrysosporium

The genomic analysis of $P$. carnosa revealed that among the most remarkable differences between this organism and P. chrysosporium was the apparent enrichment in $\mathrm{P} 450$ genes and the difference in distribution of LiP and MnP genes. P. carnosa has been mainly isolated from softwood wood species, and so an interesting prospect is that growth of this organism on softwood is facilitated

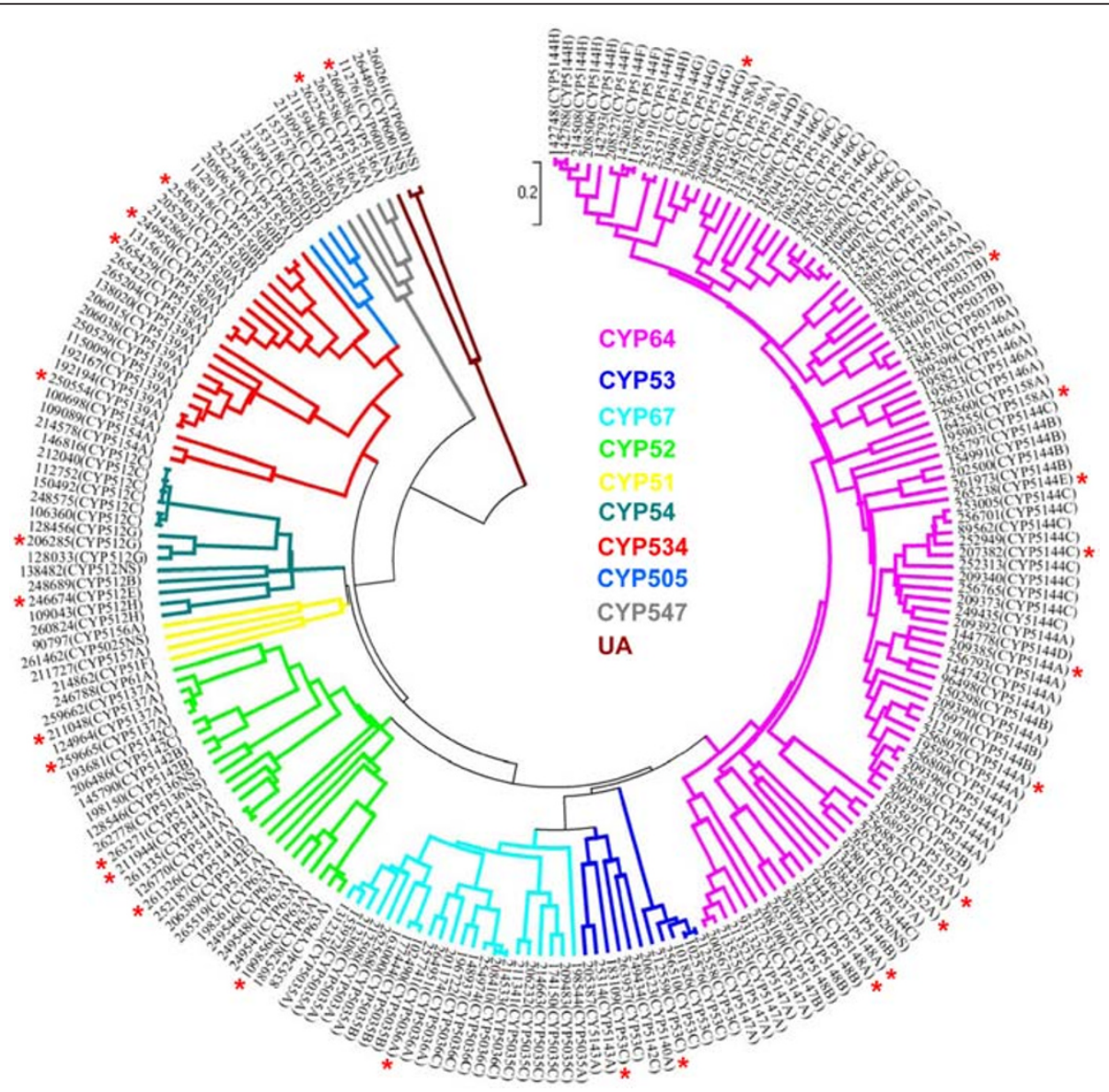

Figure 4 Phylogenetic tree of $P$. carnosa cytochrome P450 proteins (P450ome). Phylogenetic analyses were conducted in MEGA4 using the UPGMA method [75]. A total of 210 P450s ( $\geq 330$ amino acids length) were grouped under ten existing clans and one unassigned clan (UA), with clans shown in different colors. P450 members that were upregulated in wood degrading cultures [10] are indicated with asterisks and are listed in Additional file 1: Table S15. 


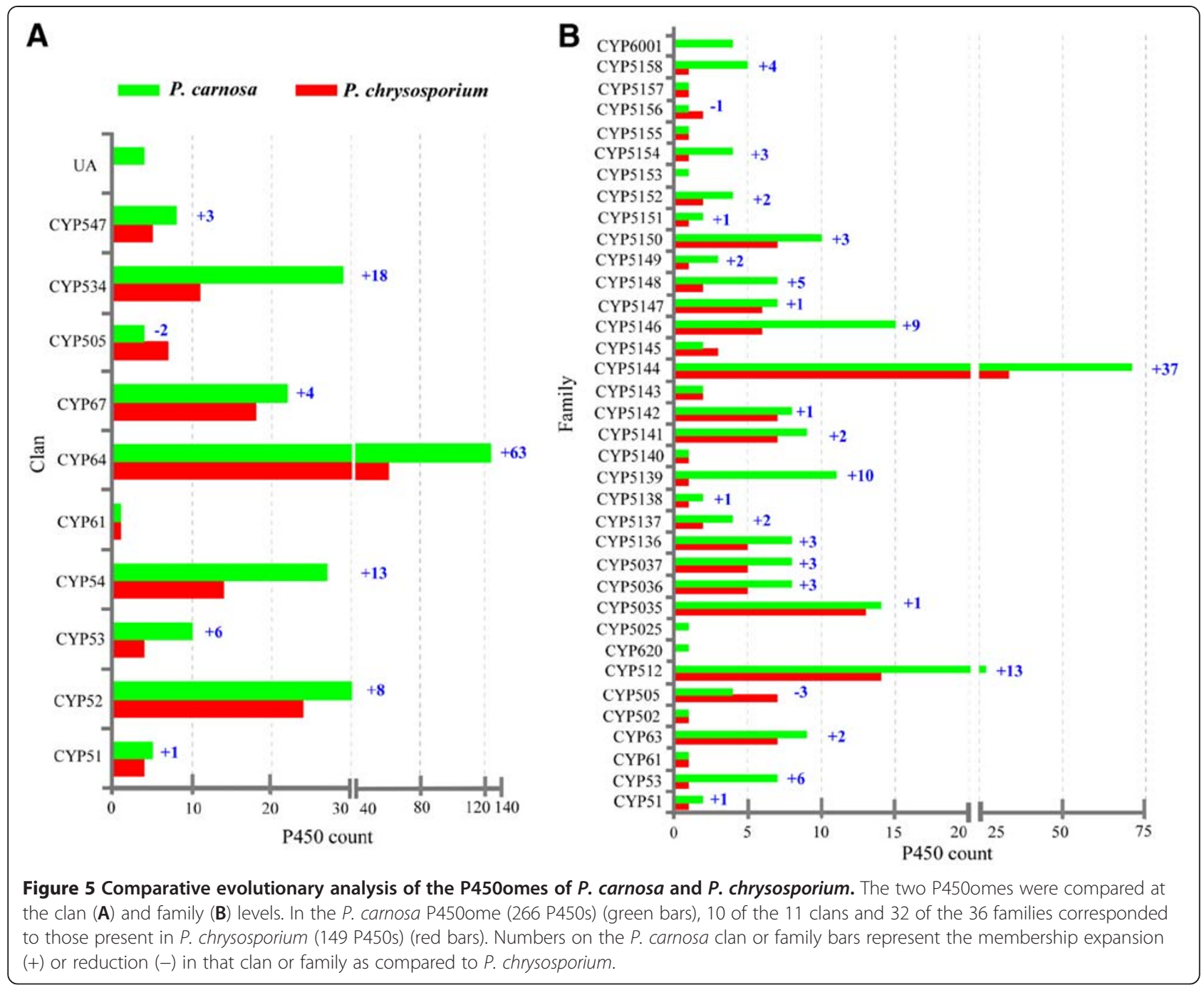

by the oxidative transformation of guaiacyl lignin and otherwise inhibitory wood extractives. To test this possibility, $P$. carnosa and $P$. chrysosporium were grown on heartwood and sapwood preparations from various hardwoods (sugar maple, yellow birch, trembling aspen) and softwoods (red spruce, white spruce, balsam fir, red pine), and residual wood extractives and lignin were measured using Ultra High Performance Liquid Chromatography (UPLC) and Fourier transform infrared spectroscopy (FT-IR), respectively.

UPLC analyses revealed that while $P$. carnosa and $P$. chrysosporium similarly reduced the total phenolic content of sapwood samples, P. carnosa transformed a higher fraction of phenolics in most of the heartwood samples, including those from softwood species containing high initial phenolic content (Figure 6). Interestingly, $P$. chrysosporium transformed a broader range of heartwood phenolics in maple than $P$. carnosa, and this trend was also observed albeit to a lower extent, for aspen heartwood (Additional file 1: Table S16).
Moreover, growth of $P$. chrysosporium on heartwood from softwood species was only observed in red spruce cultivations (Additional file 3: Figure S6), which contained relatively low initial phenolic content. In some cases, the transformation of specific phenolic compounds by $P$. carnosa could also be correlated to growth. In particular, the transformation of kaempferol 3-O- $\beta$-D-glucoside and naringin in heartwood from white spruce was higher for $P$. carnosa than $P$. chrysosporium (Additional file 1: Table S16), and $P$. carnosa exhibited better growth on white spruce (Additional file 3: Figure S6). Both kaempferol $3-\mathrm{O}-\beta-\mathrm{D}$-glucoside and naringin are sugar-containing phenolic compounds, where the sugar moiety can be released by GH1 $\beta$-glucosidase activity and GH13, GH15 or GH78 $\alpha$-rhamnosidase activity, respectively. Since GH families 1, 13, 15 and 78 did not substantially differ between $P$. carnosa and $P$. chrysosporium, detoxification of the phenolic moiety of kaempferol 3 -O- $\beta$-D-glucoside and naringin might have promoted the utilization of these compounds. 

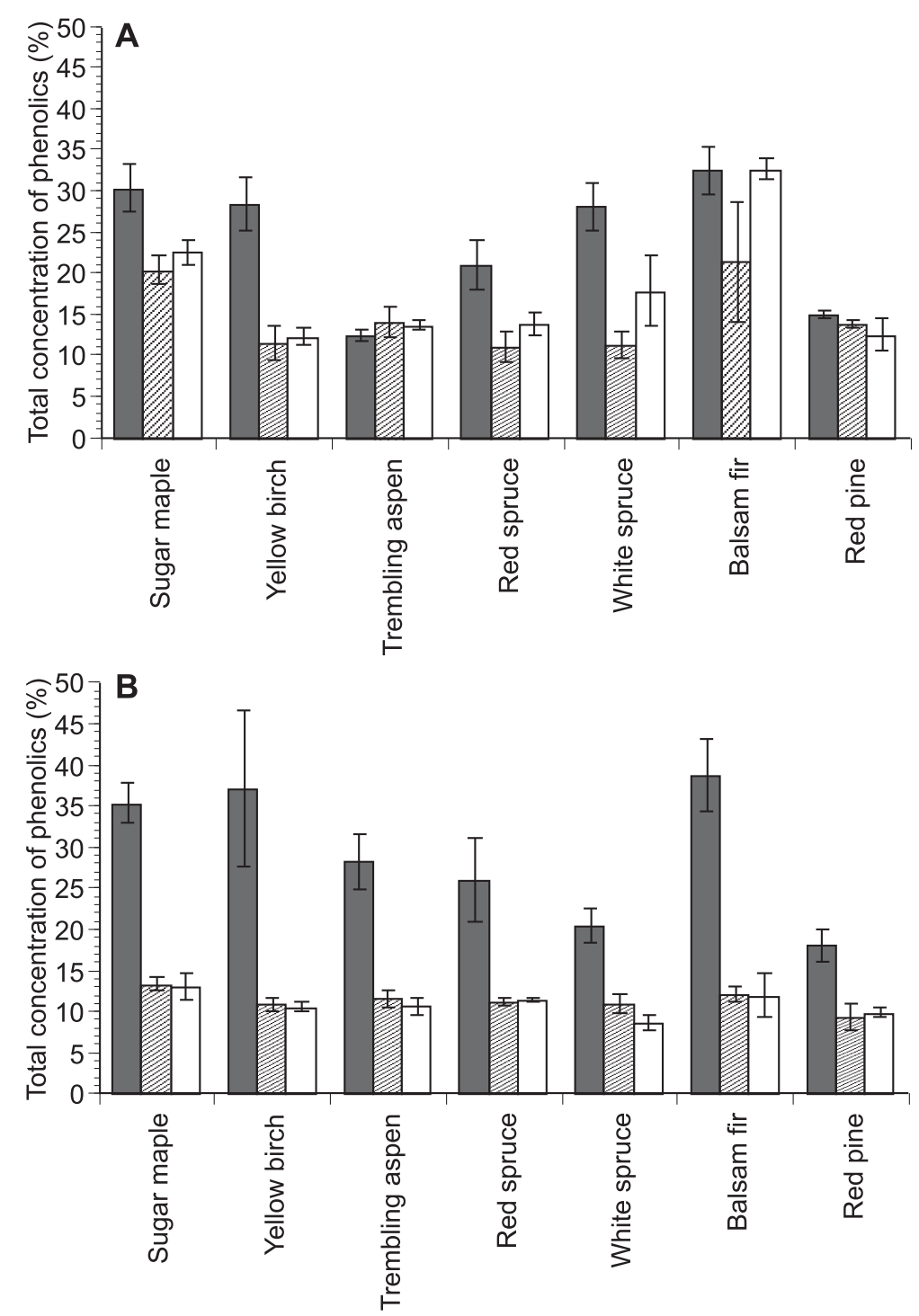

Figure 6 Concentration of phenolic compounds in whole extractives of wood samples. $P$. carnosa (lines) and P. chrysosporium (white) were grown on heartwood $(\mathbf{A})$ and sapwood $(\mathbf{B})$ wood samples at $27^{\circ} \mathrm{C}$. P. carnosa grew significantly slower than $P$. chrysosporium, and so samples were taken for analysis after 42 and 18 days of cultivation for $P$. carnosa and $P$. chrysosporium, respectively (for colony diameter, see Additional file 3: Figure S6). Grey bars indicate the phenolic content of wood samples prior to fungal cultivation. The amount of phenolics in total extractives was measured using the $\mathrm{F}-\mathrm{C}$ reagent method and calculated as percent concentration [77]. Gallic acid was used to generate a calibration curve. Error bars show the standard deviation in biological triplicates.

Aspen and pine wood samples were also analyzed by FT-IR to identify differences in lignin and carbohydrate components resulting from $P$. carnosa or P. chrysosporium cultivation. Principal component analysis (PCA) of wood FT-IR spectra in the fingerprint region (800$1800 \mathrm{~cm}^{-1}$ ) clearly separated wood samples decayed by P. carnosa and P. chrysosporium (Additional file 3: Figure S7). Overall, wood samples collected from $P$. carnosa cultivations were distinguished from control samples by a reduction in lignin (Additional file 3: Figure S7; Additional file 1: Table S17); wood samples from $P$. chrysosporium cultivations were further distinguished by more extensive polysaccharide degradation (Additional file 3: Figure S7; Additional file 1: Table S17). Notably, peak intensities at wavenumbers characteristic of cellulose absorption were reduced in heartwood pine cultivations, even though growth of $P$. chrysosporium was not visible on this wood sample (Additional file 3: Figure S6). The decay patterns revealed by the FT-IR analysis suggest that while $P$. chrysosporium is known to elicit simultaneous decay of lignin and polysaccharides, P. carnosa likely elicits sequential degradation of cell wall components. These results are 
consistent with previous reports that illustrate comparatively high expression of genes encoding lignin-degrading activities in $P$. carnosa, and cellulose-degrading activities in $P$. chrysosporium, during growth of these fungi on various wood samples $[10,11,39]$.

\section{Conclusions}

An underlying hypothesis of the current study was that identifying subtle differences in the distribution and sequence of genes encoded by $P$. carnosa and $P$. chrysosporium would facilitate the discovery of candidate enzymes that promote the conversion of recalcitrant softwood feedstocks. Indeed, the comparative genomic analysis of these related white-rot fungi revealed a tangible set of enzyme classes that could promote the conversion of softwood. In particular, this study revealed that the most divergent CAZymes belonged to families GH5, GH79, CE16, and PL14, that the relative abundance of genes encoding MnP and LiP oxidoreductases was reversed in P. carnosa compared to $P$. chrysosporium, and that $P$. carnosa encodes the largest contingent of P450 enzymes than any other basidiomycete characterized to date.

Specific hemicellulases, particularly from family GH5, were identified for future biochemical characterization. However, the clearest correlations between growth studies and differences in encoded enzymes were in regards to lignin removal and ability to transform wood extractives. While the predicted differences in the redox potential of $\mathrm{MnP}$ and LiP was consistent with slower growth of $P$. carnosa on wheat bran and cotton seed pulp compared to $P$. chrysosporium, oxidants produced by MnP might diffuse more easily through dense lignocellulose structures than LiP associated oxidants [40]. P. carnosa removed a higher proportion of phenolic extractives in heartwood samples of softwood than did P. chrysosporium; P. carnosa also showed better growth on these feedstocks. Given the comparatively high expression of P450 genes from the CYP64 and CYP52 clans in P. carnosa grown on woody substrates [10], an intriguing possibility is that the expansion of CYP64 and CYP52 families discovered through genome sequencing enables $P$. carnosa to colonize heartwood from both softwood and hardwood species. The implication of this analysis is that detoxification of wood extractives and ability to degrade dense lignin structures may be key to enhancing softwood bioconversion.

\section{Methods}

\section{Data access}

$P$. carnosa genome assembly and annotations are available via JGI Genome Portal MycoCosm [41] and DDBJ/ EMBL/GenBank under the accession AEHB00000000.

\section{Fungal strains}

Phanerochaete carnosa strain HHB-10118-sp and Phanerochaete chrysosporium strain RP-78 were obtained from the U.S. Department of Agriculture (USDA) Forest Products Laboratory (Madison, WI). These strains were maintained on YMPG agar plates under stationary conditions at $27^{\circ} \mathrm{C}$. YMPG medium contained $2 \mathrm{~g}$ yeast extract, $10 \mathrm{~g}$ malt extract, $2 \mathrm{~g}$ peptone, $10 \mathrm{~g}$ glucose, $2 \mathrm{~g}$ $\mathrm{KH}_{2} \mathrm{PO}_{4}, 1 \mathrm{~g} \mathrm{MgSO}_{4} \cdot 7 \mathrm{H}_{2} \mathrm{O}$, and $15 \mathrm{~g}$ agar per $1 \mathrm{~L}$ in $\mathrm{H}_{2} \mathrm{O}$.

\section{Confirming Homokaryosis}

Single-copy $c d h$ and fet $3 / f t r 1$ genes of $P$. carnosa were amplified by PCR and sequenced to reveal an absence of allelic polymorphism [42]. Specifically, PCR was performed using AccuPrime Pfx DNA polymerase and Reaction Mix (Invitrogen) with $160 \mathrm{ng}$ of genomic DNA and $12.5 \mathrm{pmol}$ of each primer in a $25 \mu \mathrm{L}$ reaction volume. Primers for amplification of $c d h$ (5'-TCKGARGC HGGVAAGAARGT-3' and 5'-GGVCCRATVCCGCTYT GGAA-3') were designed based on conserved sequences from six Basidiomycete fungi, and the PCR cycle was run as follows: $95^{\circ} \mathrm{C}$ for $9 \mathrm{~min}, 30$ cycles of $\left(95^{\circ} \mathrm{C}\right.$ for $1 \mathrm{~min}, 50^{\circ} \mathrm{C}$ for $2 \mathrm{~min}, 72^{\circ} \mathrm{C}$ for $2 \mathrm{~min}$ ), and $72^{\circ} \mathrm{C}$ for 15 min. Primers for amplification of fet3/ftr1 (5'TGGACGATCTGGAACTTGTG-3' and 5'-TCTCACG GAAGACGATGAAG-3') were based on the corresponding $P$. chrysosporium sequence, and the PCR cycle was run as follows: $95^{\circ} \mathrm{C}$ for $9 \mathrm{~min}, 30$ cycles of $\left(95^{\circ} \mathrm{C}\right.$ for $1 \mathrm{~min}$, $65^{\circ} \mathrm{C}$ for $2 \mathrm{~min}, 72^{\circ} \mathrm{C}$ for $3 \mathrm{~min}$ ), and $72^{\circ} \mathrm{C}$ for $15 \mathrm{~min}$. Amplified sequences were cloned into the pCR2.1-TOPO plasmid (Invitrogen) and sequenced at the Analytical Genetics Technology Centre (Toronto, ON, Canada) or the Centre for Applied Genomics (Toronto, ON, Canada). Absence of clamp connections normally produced by heterokaryons during cell division [43] was also confirmed by microscopic visualization of $P$. carnosa mycelia.

\section{Genome sequencing and assembly}

The genome was sequenced using a combination of Sanger (4 kb, $8 \mathrm{~kb}, 40 \mathrm{~kb}$ paired end), 454 (Titanium unpaired; $3.7 \mathrm{~kb}, 5.2 \mathrm{~kb}, 6.1 \mathrm{~kb}, 14.5 \mathrm{~kb}$ Titanium paired end), and Illumina ( 3 lanes of $2 \times 76 \mathrm{bp}, 0.3 \mathrm{~kb}$ insert paired end) sequencing platforms (Additional file 1: Table S1a). All general aspects of library construction and sequencing can be found at the JGI website [44]. The Illumina data was assembled with the Velvet assembler (version 0.7.55; [45]) with a hash length of 61 and the following options; -ins_length 250 -scaffolding no -exp_cov 16 -cov_cutoff 5, to produce an assembly with a final graph with 51765 nodes, n50 of 2413, max 22432, total 37740533 , using $73178660 / 94020728$ reads. Contigs greater than or equal to $800 \mathrm{bp}$ in length were shredded into $1000 \mathrm{bp}$ fragments with $800 \mathrm{bp}$ overlap to be used 
by Newbler assembler. After eliminating possible contaminant data, the combined set of velvet fragments, 454 and Sanger reads was assembled with the Newbler assembler, version 2.5-internal-10Apr08-1 with the following options; -fe reads2remove.FQC -consed -nrm -finish -info -rip -sio -g -ml 31 -mi 98 -e 48, to a final estimated assembled coverage of 58X, 1137 scaffolds with an N/L50 of 6/3.6 Mb, and 2687 contigs with an L/ N50 of 248/45.2 Kb (Additional file 1: Table S1b). One round of automated gap closure using our in house gapResolution tool [46] resulted in a final assembly with 2272 contigs with an N/L50 of 139/74.8 kb. Newbler assembled consensus EST sequence data was used to assess the completeness of the final assembly using alignment with $90 \%$ identity and $85 \%$ coverage thresholds. This resulted in $90.33 \%$ placement.

\section{cDNA library construction, sequencing and assembly}

Two clone cDNA libraries were constructed using RNA from $P$. carnosa mycelium grown in liquid YMPG medium and sequenced as described previously [47], with the minor difference that there were the two size ranges of cDNA $(0.6 \mathrm{k}-2 \mathrm{~kb}$ and $>2 \mathrm{~kb})$. The smaller cDNA insert library resulted in 9,971 ESTs for further processing and the larger insert library resulted in 9,530 ESTs. RNA purified from mycelia grown on mixed softwood was used to construct a 454 cDNA library according to the cDNA Rapid Library Preparation Method Manual (Rosch, Germany), yielding 1,139,862 ESTs for clustering and assembly. The entire set of 1,159,363 reads were assembled using Newbler (v2.3-PreRelease-6/ $30 / 2009$ ) with default parameters resulting in 16,234 contigs greater than 50 bp. and 59,361 singlets.

\section{Genome annotation}

The $P$. carnosa genome was annotated using the JGI annotation pipeline, which takes multiple inputs (scaffolds, ESTs, and known genes) and runs several analytical tools for gene prediction and annotation. Results were deposited in the JGI Genome Portal [48], a part of the integrated fungal resource MycoCosm [42] for further analysis and manual curation.

Genomic assembly scaffolds were masked using RepeatMasker [49] and the RepBase library of 234 fungal repeats [50]. tRNAs were predicted using tRNAscan-SE [51]. Using the repeat-masked assembly, several gene prediction programs falling into three general categories were used: 1) ab initio - FGENESH [52]; GeneMark [53], 2) homology-based - FGENESH+; Genewise [54] seeded by BLASTx alignments against GenBank's database of non-redundant proteins (NR: [55]), and 3) EST-based EST_map [56] seeded by EST contigs. Genewise models were extended where possible using scaffold data to find start and stop codons. EST BLAST alignments [57] were used to extend, verify, and complete the predicted gene models. The resulting set of models was then filtered for the best models, based on EST and homology support, to produce a non-redundant representative set of 13,937 gene models with characteristics described in Additional file 1: Table S2. This representative set was subject to further analysis and manual curation.

Predicted gene models were functionally annotated using SignalP [58], TMHMM [59], InterProScan [60], and BLASTp [61] against the National Center for Biotechnology Information $\mathrm{nr}$ database, and hardwareaccelerated double-affine Smith-Waterman alignments [62] against [63] KEGG [64] and KOG [65]. KEGG hits were used to assign EC numbers [66], and Interpro and SwissProt hits were used to map GO terms [67]. Functional annotations of the representative set of genes are summarized in Additional file 1: Table S3 and Table S4. Multigene families were predicted with the Markov clustering algorithm (MCL [68]) using BLASTp alignment scores between proteins as a similarity metric.

\section{Carbohydrate active enzymes}

All P. carnosa protein models were subjected to a procedure combining BLAST and HMMer3 searches against sequence libraries and HMM profiles derived from the families of glycoside hydrolases, polysaccharide lyases, carbohydrate esterases, glycosyltransferases and carbohydrate-binding modules featured in the CAZy database [15,69]. The models corresponding to glycoside hydrolase families GH1, GH2, GH3, GH5, GH6, GH7, GH9, GH10, GH11, GH12, GH16, GH28, GH31, GH43, GH45, GH51, GH53, GH55, GH61, GH74, GH79, GH115, carbohydrate esterase families CE1, CE15, CE16, carbohydrate-binding module family CBM1, as well as cellobiose dehydrogenase and cellulose-binding cytochrome $b_{562}$ [70] were manually checked using TBLASTN against the P. carnosa assembly database [48]. Gene models used for BLAST were obtained from the $P$. chrysosporium genome database $[6,71]$. In the case of multi-domain proteins, sequences encoding CBM and its associated domains were separately used as separate queries. TBLASTN programs were performed with an expectation value of $1.0 \mathrm{E}^{-1}$, and all other settings at default values.

\section{Sugar transporters}

Protein models that were annotated as predicted sugar transporters and/or permeases in the $P$. carnosa genome portal v1.0 were used as queries for BLASTp against the NCBI protein database [55] and the $P$. chrysosporium genome portal version 2 to confirm these annotations. Annotations were considered accurate when either BLAST search gave an alignment to a predicted protein with an E-value of $<1 \mathrm{e}-10$ and a score of $\geq 200$. 
The $P$. carnosa genome was then re-searched using the $P$. chrysosporium genes selected above as queries to confirm that all of the gene models relevant to this analysis were selected.

For the phylogenetic analysis, multiple alignment was performed using MAFFT version 6 software [72] with the E-INS-i algorithm. The phylogenetic tree was then constructed from the multiple alignment using the bootstrapped neighbor-joining method (1000 bootstraps), and drawn using FigTree version 1.3.1 [73]. This analysis included 28 gene models from $P$. carnosa and 25 gene models from $P$. chrysosporium, while partial gene fragments were removed.

\section{Oxidoreductases}

The BLASTp algorithm available through the JGI Fungal Genomics Program website [41] was used with default settings to search Agaricomycotina gene catalogue proteins against reference proteins. Hits were then blasted against the NCBI database [55] with default settings, and aligned to the reference protein sequences using the tool at the Genestream Bioinformatics Resource server [74]. Sequences were annotated to the reference protein when the bests hits to NCBI represented sequences of interest and the alignment showed at least 30\% amino acid identity to the reference protein. Reference proteins were chosen based on biochemical evidence supporting their identity, and correspond to the following Genbank accession numbers: LO1 (laccase) LAC2_PLEOS, LO2 (peroxidases) LIG8_PHACH, LO3 (cellobiose dehydrogenase) CDH_PHACH, LDA1 (aryl alcohol oxidase) AAC72747, LDA2 (vanillyl-alcohol oxidase) VAOX_PENSI, LDA3 (glyoxal oxidase) AAA33747, LDA4 (pyranose oxidase) P2OX_PHLGI, LDA5 (galactose oxidase) XP_959153, LDA6 (glucose oxidase) XP_002910108, LDA7 (benzoquinone reductase) AAD21025, LDA8 (alcohol oxidase) AAB57849, methanol oxidase ALOX_PICAN, quinone reductase AF465406.

\section{P450 monooxygenases}

Initial determination of the putative cytochrome $\mathrm{P} 450$ gene models in $P$. carnosa was made by searching the JGI whole genome database for the term 'P450'. The resulting putative sequences were subjected to BLAST analysis and searched for the presence of the conserved P450 signature domains namely, the oxygen-binding motif 'EXXR' and the heme-binding motif 'CXG'. P450s that showed both the domains were considered authentic and were grouped into families and subfamilies based on the existing nomenclature criteria of $>40 \%$ amino acid homology for assigning a family and $>55 \%$ for a subfamily. The families were then grouped into P450 clans, a higher order level of nomenclature that represents a cluster of P450 families across species, grouped based on relationships that are beyond the family designations [57]. P450 superfamily nomenclature rules were followed for assigning the clan, family and sub-family classification as earlier applied for P450ome classification in the model white-rot fungus, $P$. chrysosporium [34]. P450s that did not have P. chrysosporium P450 homologues were annotated based on the phylogenetic alignment with other P450s on the phylogenetic tree; the tree was constructed using Mega 4 via the bootstrap UPGMA method [75]. P450s showing both the conserved domains and a reasonable deduced protein length ( $\geq 330 \mathrm{aa}$ ) were used for the tree construction.

\section{Metabolic network reconstruction}

The $P$. carnosa metabolic network was reconstructed using version 15 of the Pathway Tools Software from SRI International Inc [76]. This network was primarily constructed from the annotation using Enzyme Commission, Gene Ontology identifiers as well as name matching algorithms. The reconstructed metabolic network contained 1166 metabolites, 1630 enzymatic reactions and 11 transport reactions that were linked to 3292 enzymes. The completed network is available at [31].

\section{Cultivation on model and wood substrates}

$P$. carnosa and $P$. chrysosporium were grown in duplicate on modified Kremer and Wood medium containing 1.5\% agar with 35 different model carbon sources [19] for 13 and 3 days, respectively, after which pictures of the plates were taken to compare colony diameter and thickness. Relative growth was determined by comparing the radius and density of the mycelia on a particular carbon source to that on D-glucose; relative growth profiles were then compared between the two fungal species. The extent of growth relative to plates containing glucose are categorized from high to non-detectable using the following designations:,,,,++++++ \pm- . No differences were observed between duplicates on any of the substrates, so only one of the pictures is presented. Monomeric and oligomeric carbon sources were used at a final concentration of $25 \mathrm{mM}$, while pure polymers were used at a final concentration of $1 \%$. Crude plant biomass was used at a final concentration of $3 \%$. This procedure allows consistent, qualitative assessment of colony development on many substrates; it has been performed routinely for more than 100 fungal species and showed good overall correlations with the genome content of these species $[16,18,19]$.

The following hardwood and softwood species were used for wood cultivations: sugar maple (Acer saccharum), yellow birch (Betula alleghaniensis), trembling aspen (Populus tremuloides), red spruce (Picea rubens), white spruce (Picea glauca), balsam fir (Abies balsamea), 
and red pine (Pinus resinosa). All wood samples were obtained from New Brunswick, Canada. A $50 \mathrm{~cm}$ bolt at $80 \mathrm{~cm}$ and $130 \mathrm{~cm}$ trunk heights were cut from each wood species. Sapwood and heartwood sections were then separated, air-dried, and processed separately using a Wiley mill (Thomas scientific, NJ, USA). Resultant wood powder was sifted using $2 \mathrm{~mm}$ and $0.425 \mathrm{~mm}$ diameter mesh sieves and powder that passed through the $2 \mathrm{~mm}$ sieve but was retained by the $0.425 \mathrm{~mm}$ sieve was recovered. Four grams of wood powder were placed on top of $5 \mathrm{~g}$ vermiculite powder ( $<1 \mathrm{~mm}$ dia.) in a glass petri dish measuring $9 \mathrm{~cm}$ in diameter; $20 \mathrm{~mL}$ of $\mathrm{H}_{2} \mathrm{O}$ was gently added to the dish, and the dish was then autoclaved for $20 \mathrm{~min}$. A $0.5 \mathrm{~cm}$ dia. agar plug taken from the growing edge of $P$. carnosa or $P$. chrysosporium cultivated on YMPG agar plates was then transferred to the centre of each plate, and incubated at $27^{\circ} \mathrm{C}$ under stationary conditions. To maintain moisture content, $5 \mathrm{~mL} \mathrm{H}_{2} \mathrm{O}$ was added to each plate every week during cultivation. Fungal growth was quantified by measuring the diameter of the fungal colony growing on each wood powder. Three replicate cultivations were prepared for each fungal and wood species.

\section{Extractives analysis}

An accelerated solvent extraction method (DIONEX, Application Note 335) was used to isolate wood extractives. To obtain standard samples for baseline analysis, $2 \mathrm{~g}$ of non-treated heartwood and sapwood samples from each wood species were mixed with approximately $0.45 \mathrm{~g}$ of diatomaceous earth, and then transferred to an $11 \mathrm{~mL}$ cell; the headspace in the cell was then filled with sand. Extraction was performed as follows; preheat $0 \mathrm{~min}$, heat $5 \mathrm{~min}$, static $5 \mathrm{~min}$, flush $90 \%$, purge $60 \mathrm{sec}$, cycles 5 , pressure $1000 \mathrm{PSI}$, temperature $100^{\circ} \mathrm{C}$, solvent $70 \% \mathrm{MeOH}$ and $30 \% \mathrm{H}_{2} \mathrm{O}$ (vol/vol). To obtain extractives from fungaltreated and control samples, each sample was mixed with solvent $\left(70 \% \mathrm{MeOH}, 30 \% \mathrm{H}_{2} \mathrm{O}(\mathrm{vol} / \mathrm{vol})\right)$ in a 10:1 ratio (solvent $(\mathrm{mL})$ :sample weight $(\mathrm{mg})$ ) and incubated for $24 \mathrm{~h}$ on an orbital shaker at room temperature, and then filtered. Supernatant was collected and a second extraction was performed on the filtered wood samples. Supernatants from the first and second extractions were combined, concentrated using a rotary evaporator, and then dried using a nitrogen evaporator.

Extractives were analyzed using Ultra performance liquid chromatography (UPLC). UPLC analysis was performed using a Waters Acquity Ultra Performance Liquid Chromatography equipped with a computer and Masslynx software, a binary solvent manager, a sample manager and an autoscan photodiode array spectrophotometer detector (PDA e $\lambda$ ). The UPLC was equipped with an Acquity UPLC BEH C18, $1.7 \mu \mathrm{m}$, (2.1 x $50 \mathrm{~mm}$ i.d.) reverse-phase analytical column from Waters housing a Van Guard BEH
C18, $1.7 \mu \mathrm{m}$ pre-column. All samples were dissolved in $70 \%$ acetonitrile: $30 \% \mathrm{H}_{2} \mathrm{O}$ and diluted to a concentration of $10 \mathrm{mg} / \mathrm{mL}$ or to a minimum of $0.25 \mathrm{~mL}$. Standards included gallic acid, methyl gallate, quercetin and rutin; $0.5 \mu \mathrm{L}$ of each standard and $3 \mu \mathrm{L}$ of samples were analyzed using gradient elution as shown in Additional file 1: Table S18. Column and auto-sampler temperature were maintained at $25^{\circ} \mathrm{C}$. Two fixed detection wavelengths $(280 \mathrm{~nm}$ and $350 \mathrm{~nm}$ ) were used to monitor the eluting peaks. Resolved peaks were scanned by the photodiode array detector from 240 to $460 \mathrm{~nm}$.

The F-C reagent method was used to calculate total phenolic concentration [77]. A calibration curve was created using gallic acid at concentrations of $25 \mathrm{mg} / \mathrm{L}, 50$ $\mathrm{mg} / \mathrm{L}, 100 \mathrm{mg} / \mathrm{L}, 250 \mathrm{mg} / \mathrm{L}$, and $500 \mathrm{mg} / \mathrm{L}$ in Milli-Q water. Briefly, $20 \mu \mathrm{L}$ of sample, gallic acid standard or blank was transferred to a $2.0 \mathrm{~mL}$ cuvette; $1.58 \mathrm{~mL}$ of Milli-Q water and $100 \mu \mathrm{L}$ of F-C Reagent were then added, mixed and incubated for $5 \mathrm{~min}$. Subsequently, $300 \mu \mathrm{L}$ of sodium carbonate was added, mixed and incubated for $2 \mathrm{~h}$ at room temperature. Absorbance was measured at $765 \mathrm{~nm}$ using a Beckman 800 series spectrophotometer.

\section{FT-IR spectroscopy}

Heartwood and sapwood of trembling aspen and red pine samples were collected before and after cultivation with $P$. carnosa and $P$. chrysosporium, and powdered using the mini-beadbeater-16 (Biospec products, USA); corresponding uninoculated controls were similarly processed. Two milligrams of wood powder were mixed with $\mathrm{KBr}(200 \mathrm{mg})$ and the mixture was pelletized using a die (1.3 cm diameter) and a hydraulic press. A Bruker Tensor 27 FT-IR was used to record the absorbance between 4000 and $400 \mathrm{~cm}^{-1}$ with a resolution of $4 \mathrm{~cm}^{-1}$. Spectra representing the average of 32 scans were corrected for atmospheric vapor compensation; baseline was corrected using the rubber band method (Opus software, v. 5.0). Spectra were normalized for unit-vector and mean-centred prior to the principal component analysis (PCA) using Unscrambler v. 9.7 software.

\section{Additional files}

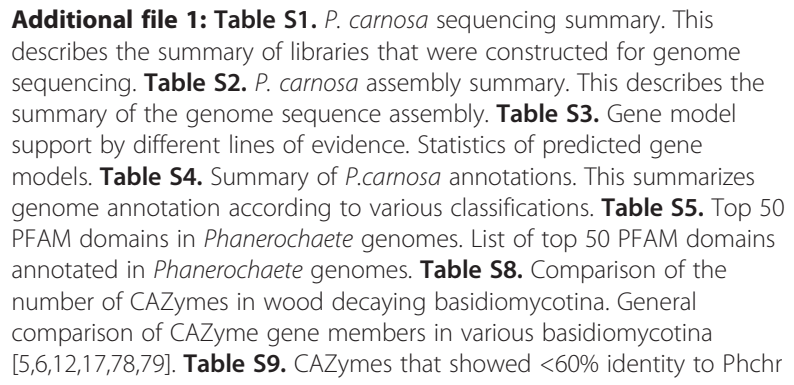


orthologs. List and gene expression data of CAZy members showing low sequence identity with orthologs in P. chrysosporium [10]. Table S11. Comparison of the number of FOLymes in P. carnosa and selected Agaricomycotina. General comparison of FOLy members between several Agricomycotina [78]. Table S12. Summary of oxidoreductases potentially involved in lignocellulose degradation by P. carnosa (Phaca) and P. chrysosporium (Phchr). Summary and comparison of specific oxidoreductase members between Phanerochaetes. Table S13. Tandem duplication of P450 genes in basidiomycete genomes. Summary table of P450 tandem duplication in known basidiomycete genomes $[5,6,12,17,78$ 80]. Table S14. P450ome classification in P. carnosa and its membership comparison with $P$. hrysosporium. Summary table of P450 members in $P$. carnosa and P. chrysosporium. Table S15. P450s upregulated in wood degrading cultures. List of P450 members in P. carnosa that were upregulated during wood degrading cultivation [10]. Table S16. UPLC peaks corresponding to wood-derived phenolic compounds that were transformed by $P$. carnosa or $P$. chrysosporium. Peak annotation and analysis of UPLC chromatograms. Table S17. Assignment of FT-IR peaks decomposed by $P$. carnosa and P. chrysosporium. Summary of the peaks detected in FT-IR analysis (Figure 57) [81-83]. Table S18. Gradient method of UPLC elution. Summarizing elution method used in UPCL analyses.

Additional file 2: Table S6. Genomic distribution of CAZymes and FOLymes on major scaffolds in P. carnosa. This table summarizes the distribution of CAZy and FOLy members located within the major scaffolds of the $P$. carnosa genome sequence.

Additional file 3: Figure S1. Pictures of $P$. carnosa and P. chrysosporium grown on various carbon sources. P. carnosa grew significantly slower than P. chrysosporium; as a result, pictures were taken after 13 and 3 days of cultivation for $P$. carnosa and $P$. chrysosporium, respectively. Cultivations were performed in duplicate and no significant differences in colony diameter or thickness were observed between the duplicates on any of the carbon sources. Monomeric and oligomeric carbon sources were used at a final concentration of $25 \mathrm{mM}$, while pure polymers were used at a final concentration of $1 \%$. Crude plant biomass was used at a final concentration of $3 \%$. Relative growth was determined by comparing the radius and density of the mycelia on a particular carbon source to that on D-glucose. The extent of growth relative to plates containing glucose are summarized as follows, from high to non-detectable:,++++ ,,,++ \pm- . This semi-quantitative, consistent assessment of both colony diameter and thickness allowed comparisons to include a broad range of substrates, including those that yield too little mycelia for accurate weight measurement, or that could interfere with protein measurements or ergosterol production $[84,85]$. Complete growth profiles of $P$. carnosa and $P$. chrysosporium, and other fungi can be found at [19]. Figure S2. Phylogenetic tree of GH61 enzymes from P. carnosa and P. chrysosporium. Proteins are labeled with protein IDs from the JGl databases for Phanerochaete carnosa v1.0 (Phaca) and Phanerochaete chrysosporium v2.0 (Phchr). The sequences were aligned using MAFFT, and the tree was drawn by FigTree. In the heatmap bar, abbreviations are; Y, YMPG; F, balsam fir; $\mathrm{P}$, lodgepole pine; $\mathrm{S}$, white spruce; $\mathrm{M}$, sugar maple [10]. Heat map represents the number of sequence reads per million $\mathrm{kb}$ as shown in this figure and described in [10], 0 (black) to 50,000 (pink). Figure S3. Phylogenetic tree of GH5 enzymes in $P$. carnosa and $P$. chrysosporium. The tree was generated as described in Figure S2. Of the 34 upregulated wood-degrading CAZymes, that were at least four times more abundant in P. carnosa grown on at least one wood substrate compared to nutrient medium, 5 (15\%) were GH5 enzymes [10]. Figure S4.

Phylogenetic tree of predicted sugar transporters and permeases from genomes of $P$. carnosa and $P$. chrysosporium. Proteins are labeled with protein IDs from the JGI database for $P$. carnosa v1.0 (Phaca) and $P$. chrysosporium v2.0 (Phchr). Protein sequences of transporters from other yeast and fungal species were used for pylogenetic comparison, including; An Aspergillus nidulans, Ao Aspergillus onyzae, Ca Candida albicans, Ci Candida intermedia, Gz Gibberella zeae, Hp Hansenula polymorpha, KI Kluyveromyces lactis, Lb Laccaria bicolor, Nc Neurospora crassa, Pp Postia placenta, Ps Pichia stipitis, Sc Saccharomyces cerevisiae, Sp Schizosaccharomyces pombe, Tm Tuber melanosporum, and Tr Trichoderma reesei. The GenBank accession numbers of corresponding sequences are: AnHyp1 (XP_682442.1), AnHyp2 (XP_660070.1), AnMstA (CAC80843),
Ao_BAE58341.1 (BAE58341.1), CaHgt1 (CAA76406), CaHgt4 (XP_723173), CaHgt11 (XP_719597), CiGxf1 (AJ937350), CiGxs1 (AJ875406), GzHyp1 (EAA74528), HpGcr1 (AAR88143), KlHgt1 (XP_451484), KIRag1 (XP_453656), KIRag4 (CAA75114), Lb_EDR07962 (EDR07962), NcHyp1 (XP_328858), NcHxt3 (CAD21508), NcNCU00801(EAA34565.1), NcNCU08114 (XP_963873.1), NcRco3 (CAE76420), Pp_115604 (EED81359), Ps ABN65648.2 (ABN65648.2), PsSut1 (AAD00266), ScHxt1 (M82963), ScHxt7 (NP_010629), ScSnf3 (P10870), SpGht1 (Q9P3U6), Tm-CAZ81962.1 (CAZ81962.1), TrHxt1 (AAR23147), TrXIt1 (shown enlarged; AY818402), TrHxt2 (DQ852622; Ruohonen and Margolles-Clark, unpublished). The sequences were aligned using MAFFT, and the tree was drawn by FigTree. In the heatmap bar, abbreviations are: Y YMPG, F balsam fir, P lodge pole pine, S white spruce, M sugar maple [10]. Group I contains a predicted monosaccharide transporter (ID 100265) and hypothetical proteins with high similarity to known sugar transporters. Group IV also contains known glucose transporters found in yeast species and cellulolytic fungi, including Trichoderma reesei and Neurospora crassa. Group V consists of high affinity glucose transporters in yeast and hexose transporters in fungal species, including the xylose transporter found in $T$. reesei [86]. Group VI and VII contains predicted sugar transporters and putative sucrose transporters (ID 89844 and 254080). Group VIII consists of predicted cellobiose transporters found in yeasts and filamentous fungi, and biochemically characterized cellodextrin transporters from $\mathrm{N}$. crassa (NcNCU00801 and 08114) [30]. Figure S5. Phylogeny, genome position, and intron distribution of genes encoding manganese peroxidases and lignin peroxidases. Protein IDs of manganese peroxidases (A) and lignin peroxidases (B) of $P$. carnosa and $P$. chrysosporium are obtained from P. carnosa v1.0 and P. chrysosporium v2.0. Alternative names are from MacDonald et al. [10] for $P$. carnosa and from Vanden Wymelenberg et al. [6] for P. chrysosporium. Figure $\mathbf{S 6 .}$ Mycelial growth of $P$. carnosa and P. chrysosporium on heartwood and sapwood samples isolated from different hardwood and softwood species. Colony diameter was measured for $P$. carnosa grown on heartwood (A) and sapwood (B), and for P. chrysosporium grown on heartwood (C) and sapwood (D). Filled square (red), sugar maple; filled circle (green), yellow birch; filled triangle (blue), trembling aspen; filled diamond (pink), red spruce; open square (purple), white spruce; open circle (orange), balsam fir; open triangle (gray), red pine. Error bars show the standard deviation in biological triplicates. Since $P$. chrysosporium mycelia was no longer visible after day 8 of cultivation on heartwood of sugar maple, yellow birch, white spruce and balsam fir, those data were not obtained. Figure S7. Different modes of wood decay described by FT-IR analysis. (A) Grouping on Principal Components (PCs) 1 and 2 for normalized FT-IR data obtained from heartwood and sapwood samples of trembling aspen and red pine after cultivation of $P$. carnosa and $P$. chrysosporium. Circle; P. carnosa, triangle; P. chrysosporium, square; control (untreated wood samples). (B) PC loadings that distinguish wood samples treated with $P$. carnosa from corresponding control samples. For example, high positive loadings describe components in control samples that were lost in the decayed samples. Loadings for PC1 are shown for trembling aspen heartwood and red pine sapwood, while loadings for PC2 are shown for trembling aspen sapwood and red pine heartwood. (C) PC loadings that distinguish wood treated with P. carnosa from corresponding wood samples treated with $P$. chrysosporium. Horizontal dotted lines at magnitude $|0.05|$ represent thresholds for loading significance. Corresponding wavenumbers $\left(\mathrm{cm}^{-1}\right)$ are indicated for peaks with significant loadings; identities of significant wavenumbers are summarized in Additional file: Table. S17. Percent values given in y-axes denote the percent of total sample variance described by the PC.

Additional file 4: Table S7. List of CAZy members computationally annotated in P. carnosa. List of protein IDs computationally annotated as CAZy members in P. carnosa.

Additional file 5: Table S10. List of the genes involved in carbohydrate metabolism. List of P. carnosa and P. chrysosporium genes involved in carbohydrate metabolism accompanied with gene expression data of $P$. carnosa.

\section{Competing interests}

The authors declare that they have no competing interests. 


\section{Authors' contributions}

HS participated in the manual gene annotation and phylogenetic analysis of CAZy enzymes and transporter proteins, fungal growth study and FT-IR analysis, and drafted the manuscript. IVG, AA, AS, KB, EL, KL, AL, and SL participated in the genome sequencing and annotation. JM confirmed homokaryosis of $P$. carnosa, prepared fungal DNA and RNA samples for sequencing and participated in sequence analysis of oxidoreductase enzymes. KS and JY participated in annotation and phylogenetic analysis of P450 enzymes. CH, Kl and MS participated in manual annotation of CAZy enzyme genes. $\mathrm{BH}$ and $\mathrm{PC}$ performed computational searches and annotation of CAZy enzymes. AW, PAvK and RPdV participated in fungal growth profiling and manual analysis of carbohydrate metabolism. YG participated in sequence alignment. RM participated in reconstruction of metabolic network. MAZ performed wood component analysis. ERM conceived of the study, participated in its design and coordination, and helped to draft the manuscript. All authors read and approved the final manuscript.

\section{Acknowledgments}

The work conducted by the U.S. Department of Energy Joint Genome Institute was supported by the Office of Science of the U.S. Department of Energy under Contract No. DE-AC02-05CH11231. This work was also supported by grants from the Natural Sciences and Engineering Research Council to E.R.M. We thank Dr. D. Cullen (Institute for Microbial and Biochemical Technology, Forest Products Laboratory, US) for his critical review of the manuscript, Dr. D. Jeremic (Department of Chemical Engineering, University of Toronto) for her assistance with FTIR data collection and analysis, and Edwin Swift from Natural Resources Canada for collecting the wood samples used in the experiments.

\section{Author details}

'Department of Chemical Engineering \& Applied Chemistry, University of Toronto, 200 College Street, Toronto, ON M5S 3E5, Canada. ${ }^{2}$ Environmental Genetics and Molecular Toxicology Division, Department of Environmental Health, University of Cincinnati College of Medicine, Cincinnati, OH 45267-0056, USA. ${ }^{3}$ US Department of Energy Joint Genome Institute, 2800 Mitchell Dr., Walnut Creek, California 94598, USA. ${ }^{4}$ Architecture et Fonction des Macromolécules Biologiques, Aix-Marseille Université, CNRS, UMR 6098, 163 Avenue de Luminy, 13288, Marseille, France. ${ }^{5}$ Department of Biomaterials Sciences, Graduate School of Agricultural and Life Sciences, University of Tokyo, I-I-I, Yayoi, Bunkyo-ku, Tokyo 113-8657, Japan. ${ }^{6}$ Great Lakes Forestry Centre, 1219 Queen Street East, Sault Ste. Marie, Ontario, CanadaP6A 2E5. ${ }^{7}$ Centre for the Analysis of Genome Evolution and Function, University of Toronto, 25 Willcocks Street, Toronto, ON, CanadaM5S 3B3. ${ }^{8}$ CBS-KNAW Fungal Biodiversity Centre, Uppsalalaan 8, 3584CT, Utrecht, The Netherlands.

Received: 17 February 2012 Accepted: 22 August 2012

Published: 2 September 2012

\section{References}

1. Galbe M, Zacchi G: A review of the production of ethanol from softwood. Appl Microbiol Biot 2002, 59:618-628.

2. Ek M, Gellerstedt G, Henriksson G: Wood Chemistry and Wood Biotechnology. Berlin: Walter De Gruyter Inc; 2009.

3. Palonen $H$, Thomsen AB, Tenkanen M, Schmidt AS, Viikari U: Evaluation of wet oxidation pretreatment for enzymatic hydrolysis of softwood. Appl Biochem Biotech 2004, 117:1-17.

4. Eriksson KE, Blanchette RA, Ander P: Microbial and enzymatic degradation of wood and wood components. New York, NY: Springer-Verlag; 1990.

5. Martinez D, Larrondo LF, Putnam N, Gelpke MD, Huang K, Chapman J, Helfenbein KG, Ramaiya P, Detter JC, Larimer F, et al: Genome sequence of the lignocellulose degrading fungus Phanerochaete chrysosporium strain RP78. Nat Biotechnol 2004, 22:695-700.

6. Vanden Wymelenberg A, Minges P, Sabat G, Martinez D, Aerts A, Salamov A, Grigoriev I, Shapiro H, Putnam N, Belinky P, et al: Computational analysis of the Phanerochaete chrysosporium v2.0 genome database and mass spectrometry identification of peptides in ligninolytic cultures reveal complex mixtures of secreted proteins. Fungal Genet Biol 2006, 43:343-356.

7. Burdsall HH: A contribution to the taxonomy of the genus Phanerochaete (Corticiaceae, Aphyllophorales). Braunschweig, Germany: J. Cramer Publisher; 1985
8. Mahajan S, Master ER: Proteomic characterization of lignocellulosedegrading enzymes secreted by Phanerochaete carnosa grown on spruce and microcrystalline cellulose. App/ Microbiol Biotechnol 2010, 86:1903-1914

9. Vanden Wymelenberg A, Gaskell J, Mozuch M, Kersten P, Sabat G, Martinez D, Cullen D: Transcriptome and secretome analyses of Phanerochaete chrysosporium reveal complex patterns of gene expression. Appl Environ Microbiol 2009, 75:4058-4068.

10. MacDonald J, Doering M, Canam T, Gong YC, Guttman DS, Campbell MM, Master ER: Transcriptomic Responses of the Softwood-Degrading WhiteRot Fungus Phanerochaete carnosa during Growth on Coniferous and Deciduous Wood. Appl Environ Microbiol 2011, 77:3211-3218.

11. Sato $S$, Feltus FA, lyer $P$, Tien $M$ : The first genome-level transcriptome of the wood-degrading fungus Phanerochaete chrysosporium grown on red oak. Curr Genet 2009, 55:273-286.

12. Martinez D, Challacombe J, Morgenstern I, Hibbett D, Schmoll M, Kubicek CP, Ferreira P, Ruiz-Duenas FJ, Martinez AT, Kersten P, et al: Genome, transcriptome, and secretome analysis of wood decay fungus Postia placenta supports unique mechanisms of lignocellulose conversion. Proc Natl Acad Sci USA 2009, 106:1954-1959.

13. Coutinho PM, Andersen MR, Kolenova K, van Kuyk PA, Benoit I, Gruben BS, Trejo-Aguilar B, Visser H, van Solingen P, Pakula T, et al: Post-genomic insights into the plant polysaccharide degradation potential of Aspergillus nidulans and comparison to Aspergillus niger and Aspergillus oryzae. Fungal Genet Biol 2009, 46:S161-S169.

14. De Koker TH, Nakasone KK, Haarhof J, Burdsall HH, Janse BJH: Phylogenetic relationships of the genus Phanerochaete inferred from the internal transcribed spacer region. Mycol Res 2003, 107:1032-1040.

15. CAZY Carbohydrate-Active enZYmes.: http://www.cazy.org/.

16. Battaglia E, Benoit I, van den Brink J, Wiebenga A, Coutinho PM, Henrissat B, Vries RP: Carbohydrate-active enzymes from the zygomycete fungus Rhizopus oryzae: a highly specialized approach to carbohydrate degradation depicted at genome level. BMC Genomics 2011, 12:38

17. Eastwood DC, Floudas D, Binder M, Majcherczyk A, Schneider P, Aerts A Asiegbu FO, Baker SE, Barry K, Bendiksby M, et al: The plant cell walldecomposing machinery underlies the functional diversity of forest fungi. Science 2011, 333:762-765.

18. Floudas D, Binder M, Riley R, Barry K, Blanchette RA, Henrissat B, Martínez AT, Otillar R, Spatafora JW, Yadav JS, et al: The Paleozoic Origin of Enzymatic Lignin Decomposition Reconstructed from 31 Fungal Genomes. Science 2012, 336:1715-1719.

19. Fungal Growth Database. www.fung-growth.org.

20. Henrissat B: A Classification of Glycosyl Hydrolases Based on Amino-AcidSequence Similarities. Biochem J 1991, 280:309-316.

21. Henrissat B, Bairoch A: Updating the sequence-based classification of glycosyl hydrolases. Biochem J 1996, 316:695-696.

22. Henrissat B, Davies G: Structural and sequence-based classification of glycoside hydrolases. Curr Opin Struc Biol 1997, 7:637-644.

23. Dupont C, Roberge M, Shareck F, Morosoli R, Kluepfel D: Substrate-binding domains of glycanases from Streptomyces lividans: characterization of a new family of xylan-binding domains. Biochem J 1998, 330:(Pt 1)41-45.

24. Eudes A, Mouille G, Thevenin J, Goyallon A, Minic Z, Jouanin L: Purification, cloning and functional characterization of an endogenous betaglucuronidase in Arabidopsis thaliana. Plant Cell Physiol 2008, 49:13311341

25. Shary S, Kapich AN, Panisko EA, Magnuson JK, Cullen D, Hammel KE: Differential expression in Phanerochaete chrysosporium of membraneassociated proteins relevant to lignin degradation. Appl Environ Microbiol 2008, 74:7252-7257.

26. Martin F, Kohler A, Murat C, Balestrini R, Coutinho PM, Jaillon O, Montanini $B$, Morin E, Noel B, Percudani R, et al: Perigord black truffle genome uncovers evolutionary origins and mechanisms of symbiosis. Nature 2010, 464:1033-1038.

27. Noguchi Y, Sano M, Kanamaru K, Ko T, Takeuchi M, Kato M, Kobayashi T: Genes regulated by AoXInR, the xylanolytic and cellulolytic transcriptional regulator, in Aspergillus oryzae. Appl Microbiol Biot 2009, 85:141-154

28. Tian CG, Beeson WT, lavarone AT, Sun JP, Marletta MA, Cate JHD, Glass NL: Systems analysis of plant cell wall degradation by the model filamentous fungus Neurospora crassa. Proc Natl Acad Sci USA 2009, 106:22157-22162. 
29. Vanden Wymelenberg A, Gaskell J, Mozuch M, Sabat G, Ralph J, Skyba O, Mansfield SD, Blanchette RA, Martinez D, Grigoriev I, et al: Comparative Transcriptome and Secretome Analysis of Wood Decay Fungi Postia placenta and Phanerochaete chrysosporium. Appl Environ Microbiol 2010, 76:3599-3610.

30. Galazka JM, Tian CG, Beeson WT, Martinez B, Glass NL, Cate JHD: Cellodextrin Transport in Yeast for Improved Biofuel Production. Science 2010, 330:84-86.

31. Metabolic network of P. carnosa and P. chrysosporium www.biozone. utoronto.ca/CASR-Phaca-Phchr.php.

32. Levasseur A, Piumi F, Coutinho PM, Rancurel C, Asther M, Delattre M, Henrissat B, Pontarotti P, Record E: FOLy: an integrated database for the classification and functional annotation of fungal oxidoreductases potentially involved in the degradation of lignin and related aromatic compounds. Fungal Genet Biol 2008, 45:638-645.

33. Rodriguez-Rincon F, Suarez A, Lucas M, Larrondo LF, de la Rubia T, Polaina J, Martinez J: Molecular and structural modeling of the Phanerochaete flavido-alba extracellular laccase reveals its ferroxidase structure. Arch Microbiol 2010, 192:883-892.

34. Doddapaneni H, Chakraborty R, Yadav JS: Genome-wide structural and evolutionary analysis of the P450 monooxygenase genes (P450ome) in the white rot fungus Phanerochaete chrysosporium: evidence for gene duplications and extensive gene clustering. BMC Genomics 2005, 6:92.

35. Doddapaneni H, Subramanian V, Yadav JS: Physiological regulation, xenobiotic induction, and heterologous expression of P450 monooxygenase gene pc-3 (CYP63A3), a new member of the CYP63 gene cluster in the white-rot fungus Phanerochaete chrysosporium. Curr Microbiol 2005, 50:292-298.

36. Khajamohiddin S, Doddapaneni H, Subramanian V, Lam YW, Yadav JS: Genome-to-function characterization of novel fungal P450 monooxygenases oxidizing polycyclic aromatic hydrocarbons (PAHs). Biochem Bioph Res Co 2010, 399:492-497.

37. Khajamohiddin S, Kattamuri C, Thompson TB, Yadav JS: Cytochrome b5 reductase as an active P450 redox enzyme system in Phanerochaete chrysosporium: Atypical properties and in vivo evidences of electron transfer capability to CYP63A2. Arch Biochem Biophys 2011, In press.

38. Subramanian V, Yadav JS: Role of P450 Monooxygenases in the Degradation of the Endocrine-Disrupting Chemical Nonylphenol by the White Rot Fungus Phanerochaete chrysosporium. Appl Environ Microbiol 2009, 75:5570-5580

39. Vanden Wymelenberg A, Gaskell J, Mozuch M, BonDurant SS, Sabat G, Ralph J, Skyba O, Mansfield SD, Blanchette RA, Grigoriev IV, et al: Significant alteration of gene expression in wood decay fungi Postia placenta and Phanerochaete chrysosporium by plant species. Appl Environ Microbiol 2011, 77:4499-4507.

40. Hammel KE, Cullen D: Role of fungal peroxidases in biological ligninolysis. Curr Opin Plant Biol 2008, 11:349-355.

41. MycoCosm. http://jgi.doe.gov/fungi.

42. Li B, Nagalla SR, Renganathan V: Cellobiose dehydrogenase from Phanerochaete chrysosporium is encoded by two allelic variants. Appl Environ Microbiol 1997, 63:796-799.

43. Schmidt O: Wood and tree fungi: biology, damage, protection, and use. Berlin; New York: Springer; 2006

44. DOE Joint Genome Institute. http://www.jgi.doe.gov/.

45. Zerbino DR, Birney E: Velvet: Algorithms for de novo short read assembly using de Bruijn graphs. Genome Res 2008, 18:821-829.

46. Trong S, LaButti K, Foster B, Han C, Brettin T, Lapidus A: Gap Resolution: A Software Package for Improving Newbler Genome Assemblies. Proceedings of the 4th Annual Meeting on "Annual Meeting on Sequencing Finishing, Analysis in the Future 2009, 1.

47. Jeffries TW, Grigoriev IV, Grimwood J, Laplaza JM, Aerts A, Salamov A, Schmutz J, Lindquist E, Dehal P, Shapiro H, et al: Genome sequence of the lignocellulose-bioconverting and xylose-fermenting yeast Pichia stipitis. Nat Biotechnol 2007, 25:319-326.

48. Phanerochaete carnosa HHB-10118-Sp v1.0 http://www.jgi.doe.gov/Pcarnosa

49. RepeatMasker. http://www.repeatmasker.org/.

50. Jurka J, Kapitonov W, Pavlicek A, Klonowski P, Kohany O, Walichiewicz J: Repbase update, a database of eukaryotic repetitive elements. Cytogenet Genome Res 2005, 110:462-467.
51. Lowe TM, Eddy SR: tRNAscan-SE: A program for improved detection of transfer RNA genes in genomic sequence. Nucleic Acids Res 1997, 25:955964

52. Salamov AA, Solovyev $\mathrm{W}$ : Ab initio gene finding in Drosophila genomic DNA. Genome Res 2000, 10:516-522

53. Isono K, Mclninch JD, Borodovsky M: Characteristic features of the nucleotide sequences of yeast mitochondrial ribosomal protein genes as analyzed by computer program GeneMark. DNA Res 1994, 1:263-269.

54. Birney E, Durbin R: Using GeneWise in the Drosophila annotation experiment. Genome Res 2000, 10:547-548.

55. NCBI BLAST. http://www.ncbi.nlm.nih.gov/BLAST/.

56. SoftBerry. http://www.softberry.com/

57. Kent WJ: BLAT - The BLAST-like alignment tool. Genome Res 2002, 12:656664

58. Nielsen $\mathrm{H}$, Engelbrecht J, Brunak S, vonHeijne G: Identification of prokaryotic and eukaryotic signal peptides and prediction of their cleavage sites. Protein Eng 1997, 10v1-6.

59. Melen K, Krogh A, von Heijne G: Reliability measures for membrane protein topology prediction algorithms. J Mol Biol 2003, 327:735-744

60. Zdobnov EM, Apweiler R: InterProScan - an integration platform for the signature-recognition methods in InterPro. Bioinformatics 2001, 17v847848 .

61. Altschul SF, Gish W, Miller W, Myers EW, Lipman DJ: Basic Local Alignment Search Tool. J Mol Biol 1990, 215:403-410.

62. DeCypherSW. http://www.timelogic.com/decypher_sw.html.

63. SwissProt. http://www.expasy.org/sprot/.

64. Kanehisa M, Araki M, Goto S, Hattori M, Hirakawa M, Itoh M, Katayama T, Kawashima S, Okuda S, Tokimatsu T, Yamanishi Y: KEGG for linking genomes to life and the environment. Nucleic Acids Res 2008, 36:D480D484.

65. Koonin EV, Fedorova ND, Jackson JD, Jacobs AR, Krylov DM, Makarova KS, Mazumder R, Mekhedov SL, Nikolskaya AN, Rao BS, et al: A comprehensive evolutionary classification of proteins encoded in complete eukaryotic genomes. Genome Biol 2004, 5 .

66. ExPASy. http://www.expasy.org/enzyme/.

67. The Gene Ontology. http://www.geneontology.org/.

68. Enright AJ, Van Dongen S, Ouzounis CA: An efficient algorithm for largescale detection of protein families. Nucleic Acids Res 2002, 30:1575-1584.

69. Cantarel BL, Coutinho PM, Rancurel C, Bernard T, Lombard V, Henrissat B: The Carbohydrate-Active EnZymes database (CAZy): an expert resource for Glycogenomics. Nucleic Acids Res 2009, 37:D233-238.

70. Yoshida M, Igarashi K, Wada M, Kaneko S, Suzuki N, Matsumura H, Nakamura $\mathrm{N}$, Ohno H, Samejima M: Characterization of carbohydrate-binding cytochrome b562 from the white-rot fungus Phanerochaete chrysosporium. Appl Environ Microbiol 2005, 71:4548-4555.

71. Phanerochaete chrysosporium v2.0 http://www.jgi.doe.gov/whiterot

72. MAFFT version $6 \mathrm{http}: / /$ mafft.cbrc.jp/alignment/server/.

73. FigTree http://tree.bio.ed.ac.uk/software/figtree/.

74. The GENESTREAM network server http://xylian.igh.cnrs.fr/bin/align-guess.cgi.

75. Tamura K, Dudley J, Nei M, Kumar S: MEGA4: Molecular evolutionary genetics analysis (MEGA) software version 4.0. Mol Biol Evol 2007, 24:1596-1599

76. Karp PD, Paley SM, Krummenacker M, Latendresse M, Dale JM, Lee TJ, Kaipa P, Gilham F, Spaulding A, Popescu L, et al: Pathway Tools version 13.0: integrated software for pathway/genome informatics and systems biology. Brief Bioinform 2010, 11:40-79.

77. Waterhouse A: Detrermination of total phenolics by folin-ciocalteau colorimetry. Curr Prot in Food Anal Chem 2002, :11.1.1-11.1.8.

78. Ohm RA, de Jong JF, Lugones LG, Aerts A, Kothe E, Stajich JE, de Vries RP, Record E, Levasseur A, Baker SE, et al: Genome sequence of the model mushroom Schizophyllum commune. Nat Biotechnol 2010, 28:957-U910.

79. Stajich JE, Wilke SK, Ahren D, Au CH, Birren BW, Borodovsky M, Burns C, Canback B, Casselton LA, Cheng CK, et al: Insights into evolution of multicellular fungi from the assembled chromosomes of the mushroom Coprinopsis cinerea (Coprinus cinereus). Proc Natl Acad Sci USA 2010, 107:11889-11894.

80. Martin F, Aerts A, Ahren D, Brun A, Danchin EG, Duchaussoy F, Gibon J, Kohler A, Lindquist E, Pereda V, et al: The genome of Laccaria bicolor provides insights into mycorrhizal symbiosis. Nature 2008, 452:88-92. 
81. Faix O: Fourier Transform Infrared Spectroscopy. In Methods in Lignin Chemistry. Edited by Lin SY, Dence CW. Berlin: Springer-Verlag; 1992:83-109.

82. Faix O, Beinhoff O: FTIR Spectra of Milled Wood Lignins and Lignin Polymer Models (DHP's) with Enhanced Resolution Obtained by Deconvolution. J Wood Chem Tech 1988, 8:505-522.

83. Popescu CM, Popescu MC, Singurel G, Vasile C, Argyropoulos DS, Willfor S. Spectral characterization of eucalyptus wood. Appl Spectrosc 2007, 61:1168-1177.

84. Bermingham S, Maltby L, Cooke R: A critical assessment of the validity of ergosterol as an indicator of fungal biomass. Mycol Res 1995, 99:479-484.

85. Boyle C, Kropp B: Development and comparison of methods for measuring growth of filamentous fungi on wood. Can J Microbiol 1992, 38:1053-1060.

86. Saloheimo A, Rauta J, Stasyk OV, Sibirny AA, Penttila M, Ruohonen L: Xylose transport studies with xylose-utilizing Saccharomyces cerevisiae strains expressing heterologous and homologous permeases. Appl Environ Microbiol 2007, 74:1041-1052

doi:10.1186/1471-2164-13-444

Cite this article as: Suzuki et al: Comparative genomics of the white-rot fungi, Phanerochaete carnosa and $P$. chrysosporium, to elucidate the genetic basis of the distinct wood types they colonize. BMC Genomics 2012 13:444

\section{Submit your next manuscript to BioMed Central and take full advantage of:}

- Convenient online submission

- Thorough peer review

- No space constraints or color figure charges

- Immediate publication on acceptance

- Inclusion in PubMed, CAS, Scopus and Google Scholar

- Research which is freely available for redistribution 